Türkiye Jeoloji Bülteni
Geological Bulletin of Turkey
$61(2018) 1-22$
doi:10.25288/tjb.358160

\title{
Orta-Geç Pleyistosen Yaşlı Gürlek-Kocabaş (Denizli) ve Örtülü (Afyon) Travertenlerinin Sedimantolojik Özellikleri ve Paleoortamsal Gelişimine ait ilk bulgular (GB-Türkiye)
}

The Sedimentological Properties and Priliminary Results of Palaeoenvironmental Development of Middle-Late Pleistocene Gürlek-Kocabaş (Denizli) and Örtülü (Afyon) Travertines, SW-Turkey

\section{Ezher Toker Tagliasacchi ${ }^{1 \mathrm{a}}(\mathbb{D}$}

${ }^{I}$ Università Degli Studi Firenze, Dipertimento di Scienze della Terra, Via la Pira, 4-50121 Firenze-Italy

${ }^{a}$ Pamukkale Üniversitesi, Jeoloji Mühendisliği Bölümü, 20017 Kınıklı-Denizli

Geliş/Received : 28.06.2017 • Düzeltilmiş Metin Geliş/Revised Manuscript Received : 23.08.2017 • Kabul/Accepted : 22.09 .2017 • Bask1/Printed : 01.01 .2018 Araştırma Makalesi/Research Article Türkiye Jeol. Bül. / Geol. Bull. Turkey

Öz:Bu çalışma, benzer depolanma sistemi içerisinde çökelmiş olan Gürlek-Kocabaş (Denizli) ile Örtülü (Afyon) travertenlerinin sedimantolojik özellikleri ile bu karasal karbonatların çökelme koşullarının ve döneminin karşılaştırmalı olarak incelenmesi sonucu elde edilen ilk bulguları içermektedir. İnceleme alanları, GB-Türkiye'deki neotektonik dönemde genişleme tektoniğine bağlı olarak açılmaya başlamış birbirlerine komşu, KB-GD uzanımlı Denizli Grabeni (Gürlek-Kocabaş) ile KD-GB uzanımlı Acıgöl Grabeni (Örtülü) içinde yer almaktadır.

Gürlek-Kocabaş travertenlerinin bataklık-havuz ve havuz düzlüğu fasiyeslerinin gözlendiği, sı ğ-havuz gibi çöküntü depolanma sistemi içinde çökelmiş olduğu, Örtülü travertenlerinin ise, yer yer ortam enerjisinin daha yüksek olduğu yamaç depolanma sisteminde ve aynı zamanda sı̆̆, otsul, enerjisi daha düşük sığ-havuz depolanma sisteminde çökelmiş olabileceği yapılan bu çalışmada belirlenmiştir. Gürlek-Kocabaş travertenlerinin yanal devamlılığı yüzlerce metre sürerken, Örtülü travertenleri, birkaç yüz metre devam etmekte ve daha sonra Acıgöl Graben'ine doğru akarsu tufalarına geçiş göstermektedir. Paleosol seviyeleri, iki traverten çökelinde de belirgin olarak gözlenmektedir. Elde edilen ilk polen verilerine göre, genellikle otsul ve açık tohumlu bitkilere ait polenlerin varlığ (Pinaceae, Cedrus, Artemisia, Quercus) bölgede iklimsel salınımlar açısından da önemli veriler içermektedir. İncelenen örneklerde Artemisia formunun varlığı, bu karasal karbonatların çökeliminde, serin ve kurak iklim koşullarını işaret etmektedir.

U/Th radyometrik yaş tayinlerine göre, iki traverten çökeli Orta-Geç Pleyistosen döneminde çökelmiş ancak GürlekKocabaş travertenleri, çökelimine 85 bin yıl'a kadar devam etmiş olmasına rağmen, Örtülü travertenlerinin çökelimi yaklaşık 308 bin yıl önce tamamen sonlanmış olduğu bu çalışmada belirlenmiştir.

Anahtar Kelimeler: Depolanma ortamları, GB-Türkiye, litofasiyes, Orta-Geç Pleyistosen, palinoloji, traverten

Abstract: This study includes the prilimary results of the Gürlek-Kocabaş (Denizli) and Örtülü (Afyon) travertines precipitated within the similar depositional systems and the comparative investigation of the sedimentary processes and depositional periods of these terrestrial carbonates. The investigated areas are located within the NW-SE trending Denizli Graben (Gürlek-Kocabaş) and NE-SW trending Acigöl Graben (Örtülü) that adjacent to each other which started to develop due to the extentional tectonic regime in the neotectonic period in SW-Turkey.

Gürlek-Kocabaş travertines are deposited in shallow-pool like depression depositional system where the marshpool and flat-pool facies are observed. On the other hand Örtülü travertines have been determined in this study where could be precipitated in higher energy environment like slope depositional system and also in lower energy environment like shallow-pool depositional system. While the lateral expanded of the Gürlek-Kocabas travertines is hundreds of meters, the Örtülü travertines continued few hundred meters and then they changed to the fluvial tufas 
towards Acigöl Graben. Palaeosol levels are significantly observed in two travertine deposits. According to the first pollen data, the existence of pollens (Pinaceae, Cedrus, Artemisia, Quercus), which are generally belonging to herbaceous and gymnosperms plants, are important data of climatic fluctuation. The presence of the Artemisia form in the investigated samples suggests the cool and arid climatic conditions in the precipitation of these terrestrial carbonates.

According to radiometric dating, two travertine deposits are precipitated in Middle-Late Pleistocene. In this study is also determined that Gürlek-Kocabaş travertines continued to precipitate until 85 ka but Örtülü travertine accumulations ceased approximately $308 \mathrm{ka}$ ago.

Keywords: Depositional settings, lithofacies, Middle-late Pleistocene, palynology, SW-Turkey, travertine

\section{GíRiş}

Travertenler, tektonik bir hat boyunca yeryüzüne çıkan bikarbonatça zengin hidrotermal suların biriktirdiği, açık renkli, sıkı (kompakt) karbonat çökelleridir (Ford ve Pedley, 1996; Pentecost, 2005; Pedley, 2009). Traverten, tufa ve speleotem gibi karasal karbonatlı kaynak çökelleri, son birkaç on yıldır farklı bakış açılarından dolayı birçok araştırmaya konu olmuştur. Özellikle son yıllarda iklim ve ortam çalışmaları konusunda bu karasal karbonat çökellerinden önemli bilgiler elde edilmektedir. $\mathrm{Bu}$ nedenle, iklimsel değişimlere karşı duyarlılık gösteren traverten ve tufa gibi karasal karbonatların çalışılması, ülkemizde bulunan Kuvaterner yaşlı bu çökellerin değerini gün geçtikçe arttırmaktadır. Bu konuda ilk ayrıntılı çalışmalar, Chafetz ve Folk (1984); Altunel ve Hancock (1993a, 1993b), tarafindan travertenlerin oluşum ortamlarını, morfolojik özelliklerini anlama üzerine olmuştur. Altunel ve Hancock (1993b) Pamukkale travertenlerinde yaptıkları çalışmada, morfolojik sinıflamaya fay önü, kanal tipi ve sirt tipi traverten olarak 3 yeni traverten yapısını da bilim camiasına kazandırmıştır. Daha sonraki çalışmalar, Altunel (1996) tarafindan Denizli (Pamukkale) travertenlerinin oluşum yaşının, morfolojik özelliklerinin, neotektonizmanın bu karbonatlar üzerindeki etkisinin incelendiği araştırmalar olarak devam etmiştir. Pentecost vd. (1997)'de bu traverteninin oluşumunda mikroorganizmaların etkisi üzerinde durmuşlar ve alglerden Cyanobakteriler, Cholorophsialar ve diyatomelerin etkili olduğunu belirlemişlerdir.
Traverten çökelleriyle ilgili olarak, birçok araştırmacının yaptığı çok önemli çalışmalar mevcuttur (Andrews vd., 1997, 2000; Guo ve Riding, 1998; Hancock vd., 1999; Vermoere vd., 1999; Özkul vd., 2002; Garnett vd., 2004; Lojen vd., 2004; Pentecost, 2005; Koşun vd., 2005; Uysal vd., 2007; 2009; Brogi ve Capezzuoli, 2009; Guo ve Chaftez, 2014; Gandin ve Capezzuoli, 2014; Özkul vd., 2014; Toker vd., 2015). Bu tip çalışmalar, özellikle son yıllarda önemi daha da artan Kuvaterner yaşlı karasal karbonatların oluşum süreçlerini anlamak, depolanma modelini ortaya çıkarmak, tektonizma ile ilgili ilişkilerini belirlemek ve çökelme sırasındaki geçmişte yaşanan iklimsel salınımları yakalayıp, gelecekteki iklim değişimleri hakkında fikir sahibi olmayı hedeflemektedir.

Kuvaterner yaşı karasal karbonat çökelleri açısından oldukça zengin olan ülkemizde yapılacak olan her çalışma büyük önem arz etmektedir. Ancak, ülkemizde bu çökeller hakkında yeteri kadar veri henüz istenilen düzeyde bulunmamaktadır.

Bu çalışma, Batı Anadolu'da belirgin olarak gözlenen komşu iki graben havzasında (Denizli ve Acıgöl) yer alan, benzer depolanma sistemleri içinde gelişmiş iki traverten çökellerinin (GürlekKocabaş ve Örtülü travertenleri) karşılaştırmalı ön bulgularını içermektedir. Bu amaçla, Özkul vd. (2013) ve Toker vd. (2015) tarafindan Kocabaş ve çevresinde yapılan ayrıntılı çalışmalar ile Toker (2017) tarafindan Acıgöl Grabeni'nin 
kuzeyindeki Sarıkavak tufalarının verileri, bu çalışmada incelenen Örtülü travertenleri ile birlikte değerlendirilmeye çalışılmıştır. Acıgöl Grabeni'nin kuzeyinde, Örtülü Köyü ve çevresinde yüzlek veren Örtülü travertenlerinin fasiyes ve fasiyes ilişkilerinin yer aldığ 1 sedimantolojik incelemeler sonucu elde edilen ilk radyometrik yaşlar, izotop sonuçları ve palinolojik veriler, bu çalışmada sunulmuştur. Böylece Acıgöl Grabeni kuzeyinde belirgin olarak gözlenen traverten ve tufa çökelleri bir bütün olarak değerlendirilmiş ve Denizli Grabeni'nin güneydoğusunda gözlenen bir diğer önemli traverten çökeli (Gürlek-Kocabaş travertenleri) ile karşılaştırılarak bölgedeki karasal karbonatların gelişimine 1şı tutulmaya çalışılmıştır. Buna ek olarak, Acıgöl Grabeni kuzeyindeki bu karasal karbonatlardan elde edilen çökelim yaşlarıyla bölgede yapılacak ileriki çalışmalara önemli bir katkı sağlayacağı düşünülmektedir.

\section{BÖLGESEL JEOLOJİ}

\section{Denizli Havzası'nın Stratigrafisi}

Denizli Havzası, Batı Anadolu'daki açılma rejimi sonucu oluşmuş, kuzey ve güney kenarları normal faylarla sınırlandırılmış KB-GD uzanımlı bir grabendir (Koçyiğit, 2005; Westaway vd., 2005; Kaymakçı, 2006; Şekil 1). Bu havza, kuzeyde Pamukkale fayı, güneyde Babadağ fayı ile sinırlandırılan $50 \mathrm{~km}$ uzunluğunda ve $15-20 \mathrm{~km}$ genişliğinde Neojen ve Kuvaterner yaşlı karasal çökeller tarafindan doldurulmuş bir graben havzasıdır. Kendini sınırlayan faylar sayesinde, dünyaca ünlü Pamukkale travertenlerini ve bununla birlikte birçok hidrotermal kaynaklarını da içinde barındırmaktadır (Altunel ve Hancock, 1993a; Çakır, 1999; Şimşek vd., 2000; Özkul vd., 2002; Alçiçek vd., 2007; Kele vd., 2011; De Flippis vd., 2012; Özkul vd., 2013; Van Noten vd., 2013). Denizli havzas1, Üst Miyosen'de yarı graben olarak oluşmaya başlamış ve geçişli olarak alüvyal, fluviyal ve Pleyistosen (Gelasiyan) döneminde sığ göl (lacustirne) ortamına doğru bir gelişim göstermiştir (Westaway, 1993; Alçiçek vd., 2007). Temel kayalar, sadece grabenin üst kısımlarında gözlenmekte ve (Özkul vd., 2002; 2013) egemen olarak Menderes Masifine ait şist ve mermerlerden oluşmaktadır (Bozkurt ve Oberhansli, 2001; Erdoğan ve Güngör, 2004). Bu birimler, Likya naplarına ait allokton Mesozoyik kireçtaşları, dolomit ve jipsler, tarafından tektonik olarak üzerlenmektedir (Okay, 1989; Sözbilir, 1997, 2005; Gündoğan vd., 2008). Erken-Orta Miyosen'de Kizılburun Formasyonu, uyumsuz olarak Neojen öncesi birimlerin üzerine gelmekte ve bu formasyonun üzerine Orta Miyosen yaşlı Sazak Formasyonu ve Geç Miyosen-Geç Pliyosen yaşlı Kolonkaya Formasyonu, Denizli Grubu'nun içinde çökelmişlerdir (Sun, 1990) (Şekil 2). Asartepe Formasyonu, uyumsuz olarak Denizli Grubu'nun üzerine gelmekte ve egemen olarak traverten ve alüvyon çökellerinden oluşmaktadır (Şekil 2). Yapılan ayrıntılı sedimantolojik çalışmalarda, Denizli Grabeni'nin Erken Miyosen'de yarı graben olarak oluştuğu ve Kuvaterner döneminde asimetrik graben olarak geliştiği vurgulanmıştır (Alçiçek vd., 2007).

Traverten çökelimi, lokal fluviyal teraslarda havza içerisine doğru gençleşerek ilerlemekte (Koçyiğit 2005; Kaymakçı, 2006; Kazancı vd., 2012) ve Neojen havza dolgularının üzerini kaplamaktadır. Kuvaterner yaşlı faylar ve graben kenarları boyunca karbonat kayalar içerisinde oluşan çatlak sirtları (fissure ridge), meteorik suların izlediği yollar olmuş ve yüzeye doğru hidrotermal akış olarak yükselmiştir (Altunel ve Hancock, 1993a,b; Minissale vd., 2002; Dilsiz, 2006; Brogi ve Capezzuoli, 2009; Özkul vd., 2013). 


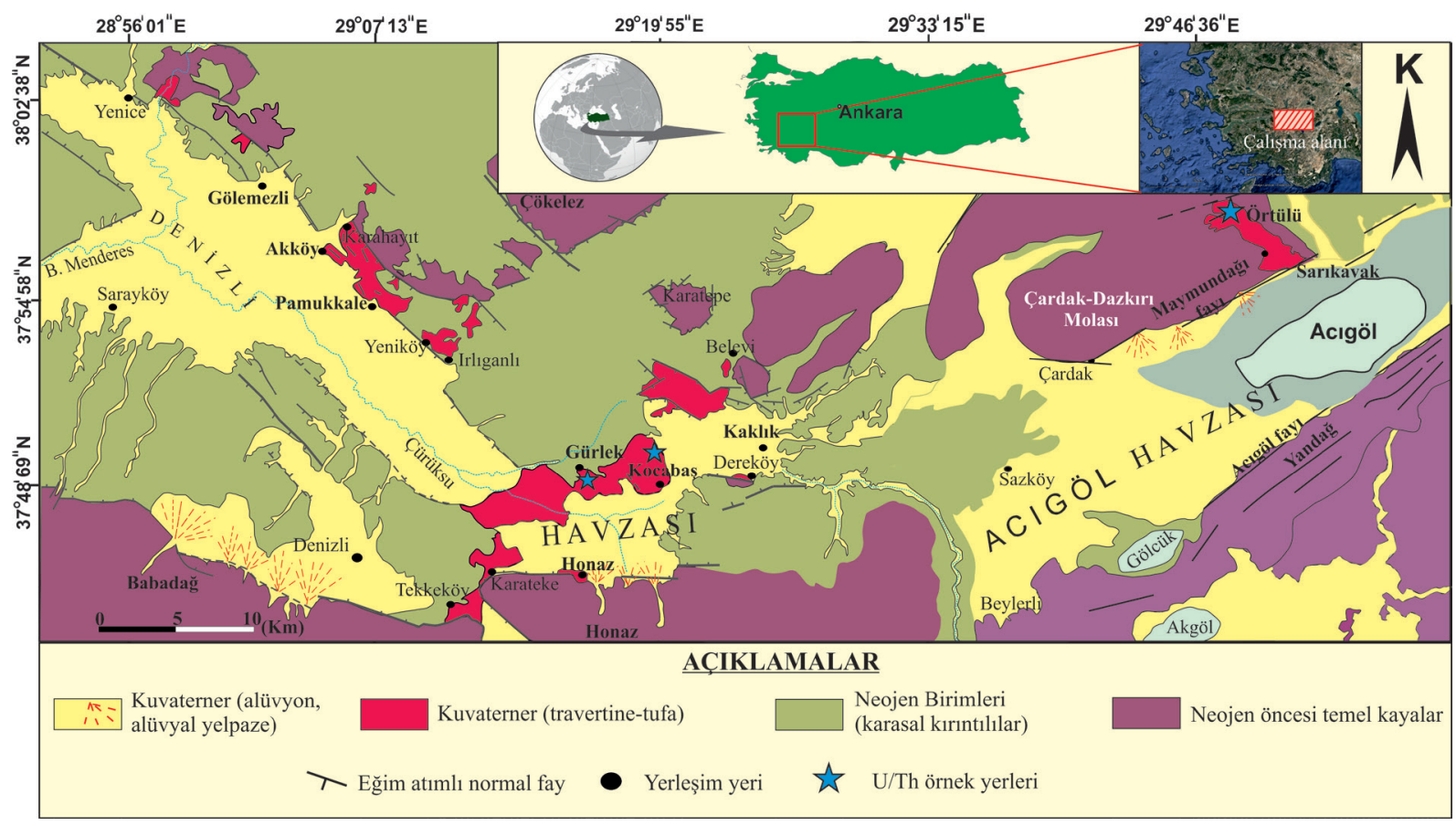

Şekil 1. Denizli ve Acıgöl Havzalarının basitleştirilmiş jeoloji haritası ve karasal karbonat çökellerinin (travertentufa) dağılımı (Sun, 1990).

Figure 1. The simplified geological map of Denizli and Acıgöl Basins and distribution of terrestrial carbonates (travertine-tufa) (after Sun, 1990).

\section{Acıgöl Havzası'nın Stratigrafisi}

Acıgöl Havzası, Denizli'nin yaklaşık $50 \mathrm{~km}$ kuzeydoğusunda bulunan, güneye doğru derinleşen KD-GB uzanımlı, asimetrik bir grabendir (Şekil 1). Graben, Batı Anadolu'da Neotektonik dönem boyunca etkin olan açılma rejimi sonucu oluşmuş, KD-GB gidişli normal faylarla sınırlandırılmış ve yaklaşık $30 \mathrm{~km}$ uzunluğunda, $10 \mathrm{~km}$ genişliğinde bir çöküntü havzasıdır (Göktaş vd.,1989; Şenel, 1997; Konak ve Şenel, 2002). Grabeni, kuzeyinde Maymundağı fayı ve güneyinde ise Acıgöl fayı olarak adlandırılan normal faylar sınırlandırmaktadır (Göktaş vd., 1989; Şenel, 1997; Toker 2009; Toker vd., 2012; Toker 2017). $\mathrm{Bu}$ ana tektonik yapılar, havza içinde $\mathrm{NaSO}_{4}$ ' $\mathrm{ca}$ zengin playa tipi bir gölün (Acıgöl) oluşmasına neden olmuşlardır. $\mathrm{Mg}-\mathrm{HCO}_{3}$ ve $\mathrm{Na}-\mathrm{SO}_{4}$ ' ca zengin yeraltı suları ve kaynak sularindan beslenen göl, mevsimsel evaporasyona bağlı $\mathrm{Na}-\mathrm{Cl}-\mathrm{SO}_{4}$ gibi sülfat çökellerini biriktirmektedir (Mutlu vd., 1999). Acıgöl grabeninin temelinde Likya naplarına ait Mesozoyik yaşı karbonat kayaçları ile ultramafik kayaçlar bulunmaktadır (Göktaş vd.,1989; Şenel, 1997; Konak ve Şenel, 2002). Likya naplarına ait bu temel kayaçlar Oligosen dönemindeki yükselme ve bölgedeki gözlenen genel bir karasallaşmadan dolayı, aşınarak molas tipi karasal kaba kırıntılıların gelişmesine neden olmuşlardır (Koçyiğit, 1984, 2005; Göktaş vd., 1989; Sözbilir, 2005; Toker, 2009; Toker vd., 2012). Bu molas tipi karasal konglomeratik birim, Üst Miyosen-Pliyosen tortulları tarafindan uyumsuz olarak üzerlenmektedir (Şekil 2). Göktaş vd., (1989) tarafindan Kizılören Formasyonu ve Akarca Formasyonu olarak adlandirılan bu Neojen yaşlı birimler, Hasandede Grubu altında incelenmiştir (Şekil 2). Daha sonraki çalışmalarda, Üst Miyosen-Pliyosen yaşlı 
konglomera, çamurtaşı-kumtaşı, killi kireçtaşımarn gibi gölsel çökellerden oluşan bu birim, Şenel (1997) tarafından Çameli Formasyonu olarak isimlendirilmiş ve bu formasyon, Kızılören üyesi, çamurtaşı-marn üyesi ve kireçtaşı üyesi olarak ayrılmıştır (Şekil 2).

\section{MATERYAL VE YÖNTEM}

İnceleme alanı olarak seçilen Gürlek-Kocabaş travertenleri 2012-2014 y1llar1 arasında ayrıntılı olarak çalışılmış (Toker vd., 2015), paleoortamsal ve paleoiklimsel gelişimini ortaya koymak

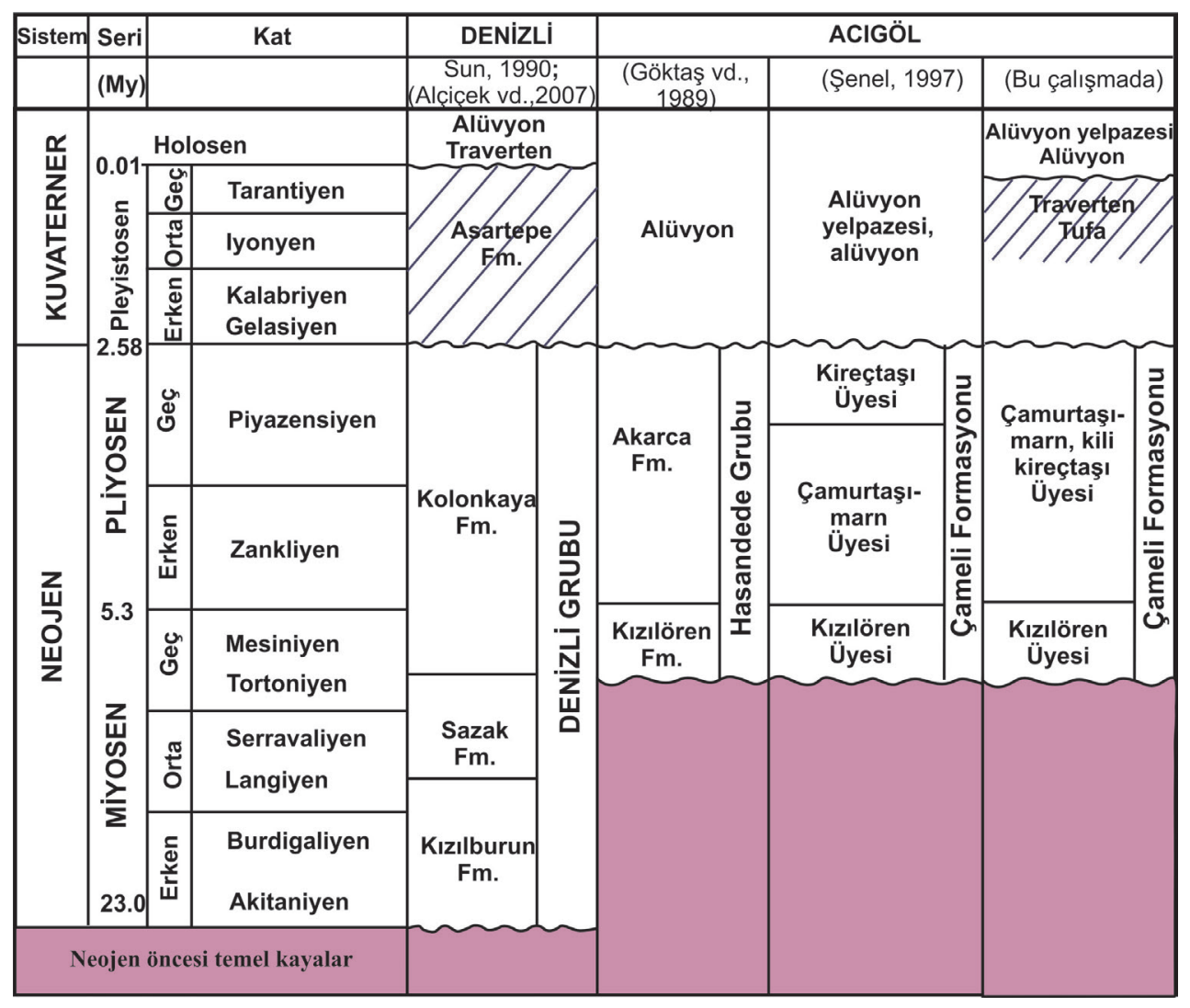

Şekil 2. Denizli ve Acıgöl Havzalarının genelleştirilmiş stratigrafik kolon kesitleri (Göktaş vd., 1989; Şenel, 1997; Alçiçek vd., 2007 çalışmalarından faydalanılmıştır).

Figure 2. Generalized stratigraphic columnar sections of Denizli and Acıgöl Basins (after from Göktaş et al., 1989; Şenel, 1997; Alçiçek et al., 2007)

Kuvaterner yaşlı karasal karbonatlar (traverten ve tufa), bu Üst Miyosen- Pliyosen yaşlı birimlerin üzerini uyumsuz olarak örtmekte ve grabenin kuzey sınırını oluşturan Maymundağ1 fayı bu genç karbonat çökellerin de sınırını oluşturmaktadır (Toker, 2009; Toker, 2017). Havzanın en genç birimlerini, alüvyon yelpazeleri ve alüvyon çökelleri oluşturmaktadır. amacıyla çeşitli analizler için örneklemeler yapılmıştır. Elde edilen analiz sonuçları, bu çalışmada Örtülü traverten çökelleri ile karşılaştırmalı olarak sunulmuştur. $\mathrm{Bu}$ amaçla, Örtülü traverten çökelinin kalınlığının belirlenmesi ve düşey yöndeki fasiyes değişimlerinin ayrıntılı olarak izlenebilmesi için terkedilmiş Örtülü traverten ocağı ve çevresinden toplam yaklaşık 
10'ar metrelik sondajlar yapılmıştır. Sondaj logundan sistematik olarak alınan örnekler, çeşitli analizler için hazır hale getirilmiştir. Ayrıca, Örtülü traverten ocağından sahada taşınabilir el karotiyeri yardımıyla yaklaşık 1» $(2.54 \mathrm{~cm})$ çapında silindirik numuneler alınarak ince kesit analizleri yapılmıştır. Toplam 75 traverten örneği, duraylı izotop, yaşlandırma ve polen analizleri için derlenmiştir. $\mathrm{U} / \mathrm{Th}$ radyometrik yaş analizi için özellikle sık1 tutturulmuş, açık renkli, kırıntı içeriğine sahip olmayan, kompakt traverten seviyelerinden örneklemeler yapılmıştır. Polen analizi için hem karbonatlı hem de paleosol seviyelerinden sistematik olarak örnekler derlenmiştir. Karotlu sondaj, Pamukkale Üniversitesi, Jeoloji Mühendisliği Bölümü'nde, ince kesit analizleri, Pamukkale Üniversitesi, Jeoloji Mühendisliği Bölümü, ince kesit laboratuvarında, duraylı izotop verileri, Arizona Üniversitesi (Amerika) izotop Jeokimya laboratuvarlarında gerçekleştirilmiştir. Yaşlandırma analizi olarak U/Th radyometrik yöntemi kullanılmış ve analizler, Geotop Quebec (Kanada), yaşlandırma laboratuvarında yapılmıştır. Palinolojik çalışmaların bir kısmı Floransa Üniversitesi, Yerbilimleri Bölümü, Palinoloji laboratuvarında yapılırken, bir kısmı da Dokuz Eylül Üniversitesi, Jeoloji Bölümü'nde gerçekleştirilmiştir.

Traverten çökellerinin litotip tanımlamaları, Guo \& Riding (1998) çalışması temel alınarak yapılmıştır. Travertenlerin çökelme sistemlerinin tanımlanmasında Guo\&Riding (1998) ve Pedley (1996) çalışmalarından yararlanılmıştır. Kırıntılı birimlerin tanımlanmasında Mial (1977) fasiyes çalışmalarından faydalanılmıştır.

\section{Gürlek-Kocabaş Traverten Çökelleri}

Gürlek-Kocabaş travertenleri, Denizli Graben Havzası'nın güneydoğu kenarında, Denizli iline bağlı Gürlek ve Kocabaş yerleşim yerlerinde belirgin olarak gözlenmektedir. (Şekil 1). Traverten çökellerinin kalınlığ $\breve{1}_{1}$ yaklaşık $40 \mathrm{~m}$ olup, 33.7 km²'lik yüzölçümüne ve tahmini 1 $\mathrm{km}^{3}$ 'lük bir hacme sahiptir (Özkul vd., 2103). $\mathrm{Bu}$ travertenlerin güneyinde Honaz traverten ve tufaları, kuzeyinde ise yaklaşı 30 traverten işletmesinin bulunduğu en geniş ve kalın KaklıkBallık traverten çökelleri bulunmaktadır (Şekil 1). Gürlek bölgesinde, başlıca laminalı (laminated), gaz baloncuklu (coated-gas bubble), kamış (reeds), ince zarflı yap1lar (paper-thin raft), havzaiçi (intraclasts) ve havza-dışı taneler (extra-clast) belirgin litotiplerdir (Toker vd., 2015). Paleosol seviyeleri, maksimum $60 \mathrm{~cm}$ kalınlığında ve traverten çökeliminin durakladığı dönemlerde depolanmışlardır. Kocabaş mevkisindeki traverten çökelleri, aktif olmayan çatlak sırtlarında gelişen yaklaşık 16 m kalınlığa sahip düşey yönde bantlı travertenlerdir (Altunel ve Karabacak, 2005; Özkul vd., 2013). Bu travertenlerde yapilan U/Th ve termolimünesans yaşlandırma tekniklerine göre, 90 bin yıl ile $>400$ bin yıl arasında bir çökelim yaşı verirken (Özkul vd., 2004; Altunel ve Karabacak, 2005; De Flippis vd., 2012; Özkul vd., 2013; Çizelge 1). Gürlek bölgesindeki travertenlerin $\mathrm{U} / \mathrm{Th}$ analiz sonuçları 85 bin yıl ile 231 bin yıl arasında yaş vermiştir (Özkul vd., 2013; Toker vd., 2015; Çizelge 2) (Şekil 3). Gürlek travertenlerinde $\delta^{13} \mathrm{C}$ izotop değerleri, \%o1,4 ile \%2,6 (V-PDB) arasında iken $\delta^{18} \mathrm{O}$ değerleri \%o $-10,5$ ile $\%$ o $-6,4$ (V-PDB) arasındadır (Toker vd., 2015). Traverten litotipleri, bataklik-havuz (marsh-pool) ve havuz düzlüğü (flat-pool) fasiyeslerini karakterize etmektedir (Toker vd., 2015). Bu travertenler, sığ-havuz veya çöküntü çökelme sistemi içinde depolanmışlardır. Gastropod ve yengeç kalıntıları oldukça belirgin olarak gözlenmektedir (Şekil 3). Palinolojik çalışmalarda elde edilen sonuçlara göre, karbonatlar içerisinde çok az polen verilerine rastlanırken, paleosol seviyeleri çok zengin palinomorflar içermektedir (Toker vd., 2015) (Şekil 4). Elde edilen bazı palinomorflar başlica, Quercus, Castanea, CompositaeTubuliflorea, Centaurea (Compositae), Poaceae, çeşitli Tricolporat polenler, fungal spor ve Zooplanktonlar'dır (Şekil 4). 

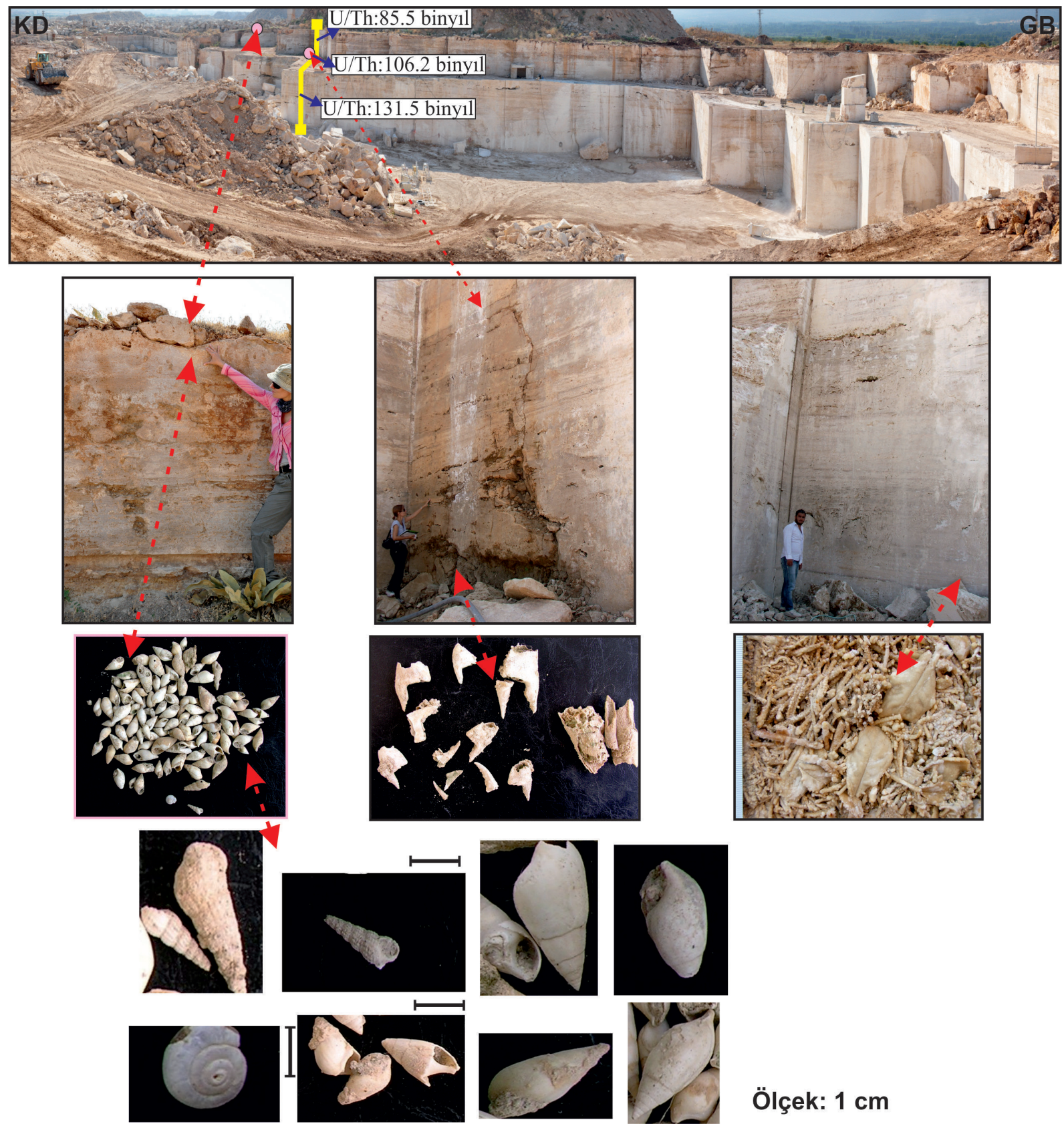

Ölçek: $1 \mathrm{~cm}$

Şekil 3. Gürlek-Kocabaş traverten ocağının panoramik görünümü (bakış yönü KB) (Toker vd., 2015). Traverten aynalarının yakından görünümü (orta) ve durgun havuz ortamını karakterize eden gastropod kavkıları (detay görüntüleri en altta), yangeç parçaları ve ayrıca fosilleşmiş bitki sap ve yaprakları.

Figure 3. The panaromic view of Gürlek-Kocabaş travertine quarry (direction of view from NW) (from Toker et al., 2015). The close to travertine benches (middle) and gastropods (details showed at bottom), crap fragments and fossilized plant root and leaf imprints. 
Çizelge 1. Gürlek-Kocabaş ve Örtülü travertenlerinin fasiyes tipleri ve depolanma ortamları

Table 1. The facies types and depositional systems of the Gürlek-Kocabaş and the Örtülü travertine deposits

\begin{tabular}{|c|c|c|}
\hline & $\begin{array}{l}\text { Gürlek-Kocabaş Travertenleri } \\
\text { (Denizli Havzas1) } \\
\text { (Özkul vd., 2013; Toker vd., 2015) }\end{array}$ & $\begin{array}{l}\text { Örtülü Travertenleri } \\
\text { (Acıgöl Havzas1) } \\
\text { (Bu çalıșmada) }\end{array}$ \\
\hline Litotip & $\begin{array}{l}\text { Laminalı, gaz kabarcıkları, } \\
\text { Çalılar (reeds), İnce zarflar (paper-thin rafts), } \\
\text { Havza-içi ve Havza-dışı taneler }\end{array}$ & $\begin{array}{l}\text { Laminalı, Çalı (shrub), ince zarflar, } \\
\text { kristalin kabuk, pizoid, havza-içi ve havza- } \\
\text { dışı taneler }\end{array}$ \\
\hline Fasiyes & $\begin{array}{l}\text { Bataklık-havuz (marsh-pool) } \\
\text { havuz düzlüğü (flat-pool) }\end{array}$ & $\begin{array}{l}\text { Teraslı yamaç fasiyesi (Terrace slope) } \\
\text { Hafif yamaç fasiyesi (Smooth slope) } \\
\text { Havuz düzlüğü (Flat-pool), } \\
\text { bataklık-havuz (marsh- pool), } \\
\text { çalı düzlüğü (shrub-flat) }\end{array}$ \\
\hline Kalınlık (m) & $\sim 40 \mathrm{~m}$ & $\sim 20 \mathrm{~m}$ \\
\hline $\begin{array}{l}\text { Yanal } \\
\text { devamlılık }\end{array}$ & Yüzlerce metre & Birkaç yüz metre \\
\hline $\begin{array}{l}\text { Erozyonal } \\
\text { yüzey }\end{array}$ & $\begin{array}{l}\text { Eski toprak (paleosol) } \\
\text { karstik boşluklar }\end{array}$ & $\begin{array}{l}\text { Eski toprak (paleosol) } \\
\text { Karstik boşluklar, mikro-dikitler } \\
\text { Erime-çözünme boşlukları }\end{array}$ \\
\hline Yaş (U/Th) & >231- 85 bin y1l (Gürlek) & $\sim 500-308$ bin y1l \\
\hline Fauna & Gastropodlar,Yengeç kalıntıları & Ostracodlar,algler \\
\hline Flora & $\begin{array}{l}\text { Arboreal plants: } \\
\text { Pinaceae (Pinus and Abies) } \\
\text { Non-arboreal plants } \\
\text { Grassland species Asteraceae-Asteroideae } \\
\text { Asteraceae-Cichorioideae } \\
\text { Poaceae }\end{array}$ & $\begin{array}{l}\text { Pinus } \\
\text { Quercus illex } \\
\text { Artemisia } \\
\text { Poaceae }\end{array}$ \\
\hline $\begin{array}{l}\text { Tektonik } \\
\text { yapılar }\end{array}$ & $\begin{array}{l}\text {-D-B uzanımlı Honaz fayı, } \\
\text {-KB-gidişli günümüzde aktif olmayan çatlak } \\
\text { sırtları, }\end{array}$ & $\begin{array}{l}\text {-KD-GB uzanımlı Acıgöl Grabeninin kuzey } \\
\text { sınırı Maymundağı Fayı } \\
\text {-Maymudağı Fayı'na paralel gelişen sintetik } \\
\text { faylar }\end{array}$ \\
\hline $\begin{array}{l}\text { Depolanma } \\
\text { Ortamı }\end{array}$ & $\begin{array}{l}\text { Çöküntü depolanma sistemi içinde durgun/düşük } \\
\text { enerjili sığ göl ortamı }\end{array}$ & $\begin{array}{l}\text {-Çöküntü Depolanma Sistemi (durgun/düşük } \\
\text { enerji) } \\
\text {-Yamaç Depolanma Sistemi (çalkantıl1/ } \\
\text { eğimli, enerji yüksek) }\end{array}$ \\
\hline
\end{tabular}

\section{Örtüllü Traverten Çökelleri}

Örtülü travertenleri, Acıgöl Graben'inin yaklaşık 5 km kuzeyinde yer alan Afyon iline bağl1 Örtülü Köyü civarında yüzlek vermektedir (Şekil 1). Bu karasal karbonatlar, Örtülü Köyü ve çevresinde hidrotermal çıkışlı traverten çökelleri olarak temsil edilirken, güneye doğru (Sarıkavak tufa) akarsu tufa çökellerine geçiş göstermekte ve graben sınırına kadar devam etmektedir (Şekil 1). Terkedilmiş traverten ocağ sondajda, Örtülü traverten çökellerinin kalınlığının toplam $20 \mathrm{~m}$ civarında olduğu, bu traverten çökellerinin Oligosen yaşlı konglomeratik istifin üzerinde depolandığ1 görülmüştür. Travertenler, laminalı (laminated), kristalin kabuk (crystalline crust), çalı (shrub), kamış (reeds), ince zarflı 
yapılar (paper-thin raft), pizolit, havza-içi taneler (intraclasts) ve havza-dışı taneler (extraclasts) gibi belirgin litotiplerden oluşmaktadır (Şekil 5). Örtülü travertenlerinde görülen sik1 ve beyaz renkli kristalin kabuk litotipi, suyun akış yönü boyunca mikro boyutta teras yapıları oluşturmaktadır (Şekil 5D). Paleosol seviyeleri oldukça belirgin ve karstik boşluklar da oldukça yaygındır. Karstik boşlukların içerisinde mikro boyutta dikitler (stalagmite) gelişmiştir (Şekil 5E). Konglomera, kumtaşı, silttaşı gibi kiremit kırmızı rengindeki kırıntılı birim, traverten çökellerinin altında tipik moloz akması şeklinde gözlenmektedir (Şekil 6B). Havza-dışı taneler, ortalama $12 \mathrm{~cm}$, maksimum $20 \mathrm{~cm}$ çapında, egemen olarak Oligosen konglomeralarına ait kireçtaşı, harzburjit, dünit gibi çakıllardan oluşmaktadır (Şekil 6B). Litotipler, hafif yamaç (smooth slope), teraslı yamaç (terrace slope), havuz düzlüğü (Flat-pool), sı̆̆ otsul havuz (marsh- pool), çalı düzlügü (shrub-flat) fasiyeslerini karakterize etmektedir. $\mathrm{Bu}$ fasiyeslerin, yanal ve düşey yönde devamlılığı ve birbirleriyle olan ilişkileri incelendiğinde, Örtülü travertenlerinin yamaç (slope) ve çöküntü (depressional) depolanma sistemleri içerisinde oluştukları görülmüştür (Şekil 5). U/Th verileri, Örtülü travertenlerinin yaklaşık 500 bin yıl önce çökelmeye başladığı ve
308 bin y1l önce traverten çökeliminin tamamen durmuş olduğunu göstermiştir (Çizelge 3; Şekil 5A, G). Önceki çalışmalarda, Sarıkavak tufa çökellerinin üst seviyelerinden elde edilen U/ Th yaş verileri, 80 bin yıl yaşı vermiştir (Toker 2017). Örtülü travertenlerinden elde edilen duraylı izotop verilerine göre $\delta^{13} \mathrm{C}$ izotop değerleri; $\%$ - 1,54 ile $\%$ 1,5 (V-PDB) arasinda ve $\delta^{18} \mathrm{O}$ izotop değerleri; \%o-10,78 ile \%o-9,76 (V-PDB) arasında değişmektedir. Örtülü traverten ocağından alınan tapa örneklerinden elde edilen ince kesit çalışmalarında, gastropodlar az da olsa bulunurken, mikrit çamuru içinde Ostrakod kavkıları ve alglere yaygın olarak rastlanılmaktadır (Şekil 6A, C ve D). Palinolojik çalışmalar, paleosol seviyelerinin daha zengin olduğunu göstermektir. $\mathrm{Bu}$ seviyelere ait örneklerde çeşitli otsul formlar (Poaceae, Asteraceae-tubuliflorea, Asteraceae, Artemisia, Asteraceae-Cichorioideae-ligulifloreae tip, Polygonaceae; Polygonum persicaria, Geraniaceae, Chenopodiaceae) bulunmuştur (Şekil 7). Ayrica, travertenlerden elde edilen polen verilerine göre gymnosperm polenlerden Pinaceae ailesine ait bitkileri (örn. Pinus, Cedrus),ve angiosperm polenlerin (örn. Quercus, Castanea) varlığ1 ve zaman zaman bolluğu belirlenmiştir (Şekil 7). 
Çizelge 2. Gürlek-Kocabaş travertenlerinden elde edilen U/Th radyometrik yaş analiz sonuçları

Table 2. U/Th dating results obtained from the Gürlek-Kocabaş travertines

\begin{tabular}{|c|c|c|c|c|c|c|}
\hline $\begin{array}{c}\text { Örnek No } \\
\text { (Toker vd., 2015) } \\
\end{array}$ & ${ }^{238} \mathbf{U}$ (ppm) & ${ }^{232} \mathrm{Th}$ (ppm) & ${ }^{234} \mathbf{U} /{ }^{238} \mathbf{U}$ & ${ }^{230} \mathrm{Th} /{ }^{234} \mathrm{U}$ & ${ }^{230} \mathrm{Th} /{ }^{232} \mathrm{Th}$ & Yaş (bin yıl) \\
\hline S1-10K & 0.3533 & 0.0045 & $1.2145 \pm \mathbf{0 . 0 0 8}$ & $0.6281 \pm 0.004$ & $184.559 \pm 1.16$ & $103.778 \pm 1.4$ \\
\hline S1-1K & 0.1372 & 0.0037 & $1.2148 \pm \mathbf{0 . 0 0 7}$ & $0.8168 \pm 0.007$ & $113.821 \pm 1.09$ & $169.335 \pm 3.8$ \\
\hline S2-10K & 0.3132 & 0.0877 & $1.2119 \pm \mathbf{0 . 0 0 7}$ & $0.6578 \pm 0.006$ & $8.6968 \pm 0.09$ & $104.000 \pm 3.9$ \\
\hline S2-1K & 0.0723 & 0.0169 & $1.2120 \pm \mathbf{0 . 0 0 8}$ & $0.8522 \pm 0.009$ & $13.5088 \pm 0.1$ & $181.267 \pm 7.7$ \\
\hline S3-14K & 0.1920 & 0.0100 & $1.393 \pm \mathbf{0 . 0 1}$ & $0.6929 \pm 0.01$ & $54.2065 \pm 0.5$ & $118.3170 \pm 3$ \\
\hline S3-12K (b) & 0.2157 & 0.0026 & $1.2184 \pm 0.03$ & $0.7058 \pm 0.01$ & $217.4143 \pm 4$ & $125.9506 \pm 3$ \\
\hline S4-39K & 0.3764 & 0.2103 & $1.4626 \pm 0.01$ & $0.6097 \pm 0.009$ & $4.8774 \pm 0.08$ & $85.512 \pm 5.8$ \\
\hline$S 4-41 K$ & 0.3450 & 0.0058 & $1.2473 \pm \mathbf{0 . 0 0 9}$ & $0.6440 \pm 0.008$ & $7.3117 \pm 0.1$ & $99.865 \pm 4.5$ \\
\hline S4-38K & 0.4051 & 0.1835 & $1.2585 \pm \mathbf{0 . 0 0 7}$ & $0.6764 \pm 0.008$ & $5.7433 \pm 0.08$ & $106.217 \pm 5.9$ \\
\hline S4-32K & 0.1282 & 0.0294 & $1.2400 \pm \mathbf{0 . 0 1}$ & $0.7377 \pm 0.01$ & $12.1999 \pm 0.2$ & $131.493 \pm 4.8$ \\
\hline S4-15K & 0.1109 & 0.0182 & $1.2263 \pm 0.009$ & $0,7474 \pm 0.01$ & $17,0234 \pm 0.2$ & $139,9060 \pm 4$ \\
\hline $\begin{array}{c}\text { Örnek No } \\
\text { (Özkul vd., 2013) }\end{array}$ & ${ }^{238} \mathbf{U}$ (ppb) & ${ }^{232} \mathrm{Th}$ (ppt) & $\delta^{234} \mathbf{U}$ & ${ }^{230} \mathrm{Th} /{ }^{238} \mathbf{U}$ & ${ }^{230} \mathrm{Th} /{ }^{232} \mathrm{Th}$ & Yaş (bin yll) \\
\hline GRL-1 & $84.17 \pm 0.60$ & $124,905 \pm 14$ & $246 \pm 10$ & $1.196 \pm 0.030$ & $13.31 \pm 0.35$ & $231,517 \pm 26,6$ \\
\hline GRL-2b & $184.3 \pm 1.1$ & $144,009 \pm 17$ & $275.9 \pm 8.5$ & $0.921 \pm 0.021$ & $19.47 \pm 0.49$ & $114,341 \pm 10,0$ \\
\hline GRL-3 & $159.73 \pm 0.93$ & $27,375 \pm 206$ & $282.3 \pm 8.7$ & $0.933 \pm 0.011$ & $89.9 \pm 1.2$ & $128,779 \pm 37$ \\
\hline GRL-4b & $205.7 \pm 1.2$ & $3993 \pm 101$ & $260.5 \pm 9.3$ & $0.8194 \pm 0.006$ & $697 \pm 18$ & $108,652 \pm 19$ \\
\hline KB-20 & $9.209 \pm 0.071$ & $3.3 \pm 8.4$ & $239 \pm 14$ & $0.714 \pm 0.011$ & $33,036 \pm 84,54$ & $90,463 \pm 26$ \\
\hline KB-21 & $10.560 \pm 0.08$ & $96.9 \pm 6.2$ & $152 \pm 13$ & $0.6821 \pm 0.008$ & $1228 \pm 79$ & $95,098 \pm 26$ \\
\hline KB-22 & $15.53 \pm 0.16$ & $666.1 \pm 9.1$ & $180 \pm 18$ & $0.894 \pm 0.011$ & $344.0 \pm 5,4$ & $144,908 \pm 62$ \\
\hline
\end{tabular}

Çizelge 3. Örtülü travertenlerinden elde edilen U/Th radyometrik yaş analiz sonuçları

Table 3. U/Th dating results obtained from the Örtülü travertines

\begin{tabular}{|c|c|c|c|c|c|}
\hline Örnek No (bu çalışmada) & ${ }^{238} \mathbf{U}(\mathbf{p p b})$ & ${ }^{232} \mathbf{T h}(\mathbf{p p b})$ & ${ }^{230} \mathbf{T h} /{ }^{238} \mathbf{U}$ & ${ }^{230} \mathbf{T h} /{ }^{232} \mathbf{T h}$ & Yaş (bin yl) \\
\hline $\mathbf{1 4 S K - 0 5}$ & 0.3528 & 0.6242 & 1.1897 & 2.0553 & n.d. \\
\hline $\mathbf{1 4 S K - 0 8}$ & 0.2028 & 0.0166 & 1.1308 & 42.2275 & $308.878 \pm 9.20$ \\
\hline SL-1/8 & 503,6639 & 567,6871 & 1,1425 & 3,0980 & $474,733 \pm 54$ \\
\hline SL-1/5-1 & 390,7400 & 399,6334 & 1,1388 & 3,4031 & $436,642 \pm 34$ \\
\hline SL-1/12 & 436,2328 & 532,7401 & 1,1345 & 2,8775 & $358,613 \pm 57$ \\
\hline
\end{tabular}

n.d. yaş verisi elde edilememiştir. 


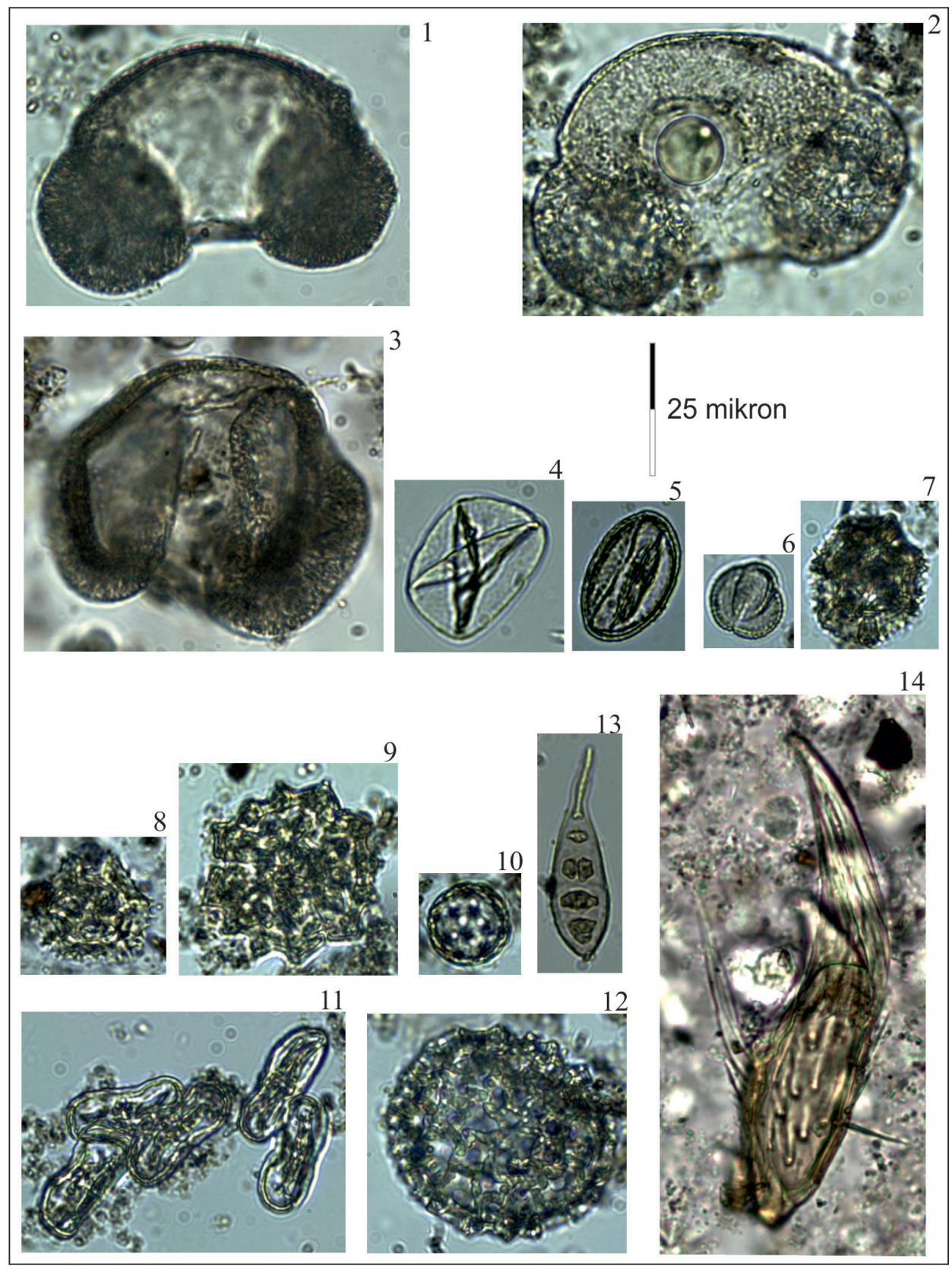

Şekil 4. Gürlek-Kocabaş travertenlerinden elde edilen palinomorflar. (1-3) Pinaceae (4) Poaceae; (5) Quercus; (6) Asteraceae, Artemisia; (7,8) Asteraceae-Cichorioideae-ligulifloreae tip (9) Asteraceae-tubuliflorea tip; (10) Chenopodiaceae; (11) Apiaceae; (12) Polygonaceae; Polygonum persicaria (13) Fungal spor; (14) Zooplankton;

Figure 4. The palinomorphs obtained from Gürlek-Kocabaş travertines. (1-3) Pinaceae; (4) Poaceae; (5) Quercus; (6) Asteracease, Artemisia; (7,8) Asteraceae-Cichorioideae-ligulifloreae; (9) Asteraceae-tubuliflorera; (10) Chenopodiceae; (11) Apiaceae; (12) Polygonaceae; Polygonum persicaria; (13) Fungal spor; (14) Zooplankton 

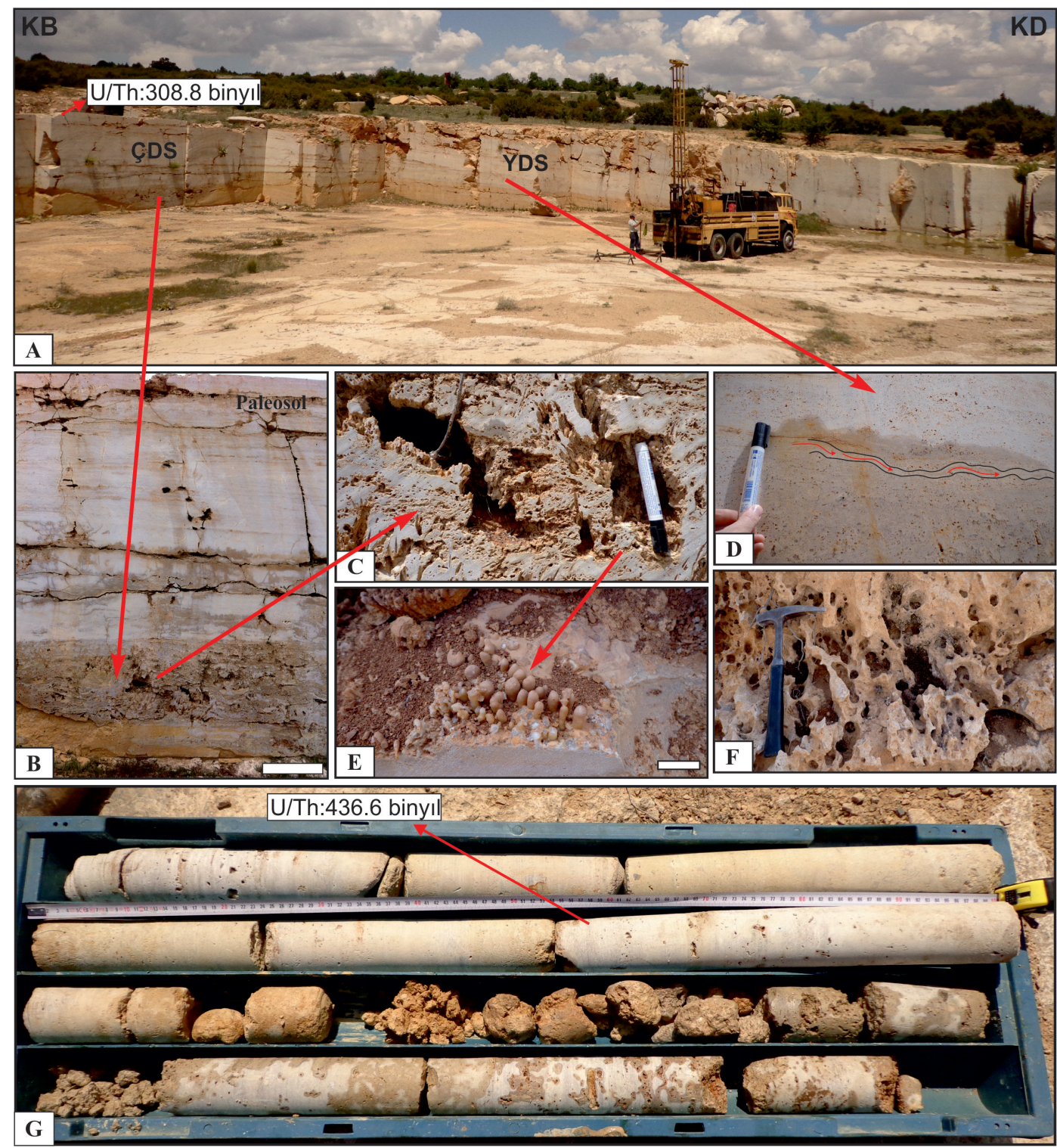

Şekil 5. (A) Çöküntü Depolanma (ÇDS) ve Yamaç Depolanma (YDS) sistemleri içinde çökelen Örtülü travertenlerinin arazideki görünümü, tavan seviyesinden alınan U/Th yaş verisi; (B) Paleosol seviyesinin üzerine kanal yapısı şeklinde kazıyarak gelişen kamış litotipleri ve (C) karstik boşluklar sonucu oluşan (E) mikro dikitler (stalagmite); (D) hafif yamaç sisteminde oluşan teraslı kristal kabuk (crystalline crust) litotipi; (F) travertenlerin üst kısımlarında gözlenen erime, çözünme boşlukları; $(\mathrm{G})$ terkedilmiş traverten sahası içinde alınan sondaj karotunun yakından görünümü ve sondaj logundan elde edilen yaş verisi.

Figure 5. (A) The panoramic view of the Örtülü travertines precipitated in Depression Depositional (DDS) and Slope Depositional (SDS) Systems; (B) Reed lithotypes occurred on palaeosol level scouring as channelized form and $(C)$ micro-stalagmites; (E) observed in karstic solutions; (D) terraced crystalline crust lithotype formed in smooth slope system; (F) dissolution cavities observed in upper part of the travertines; (G) The closer view of drilling $\log$ from abandoned quarry and dating result obtained from drilling log. 

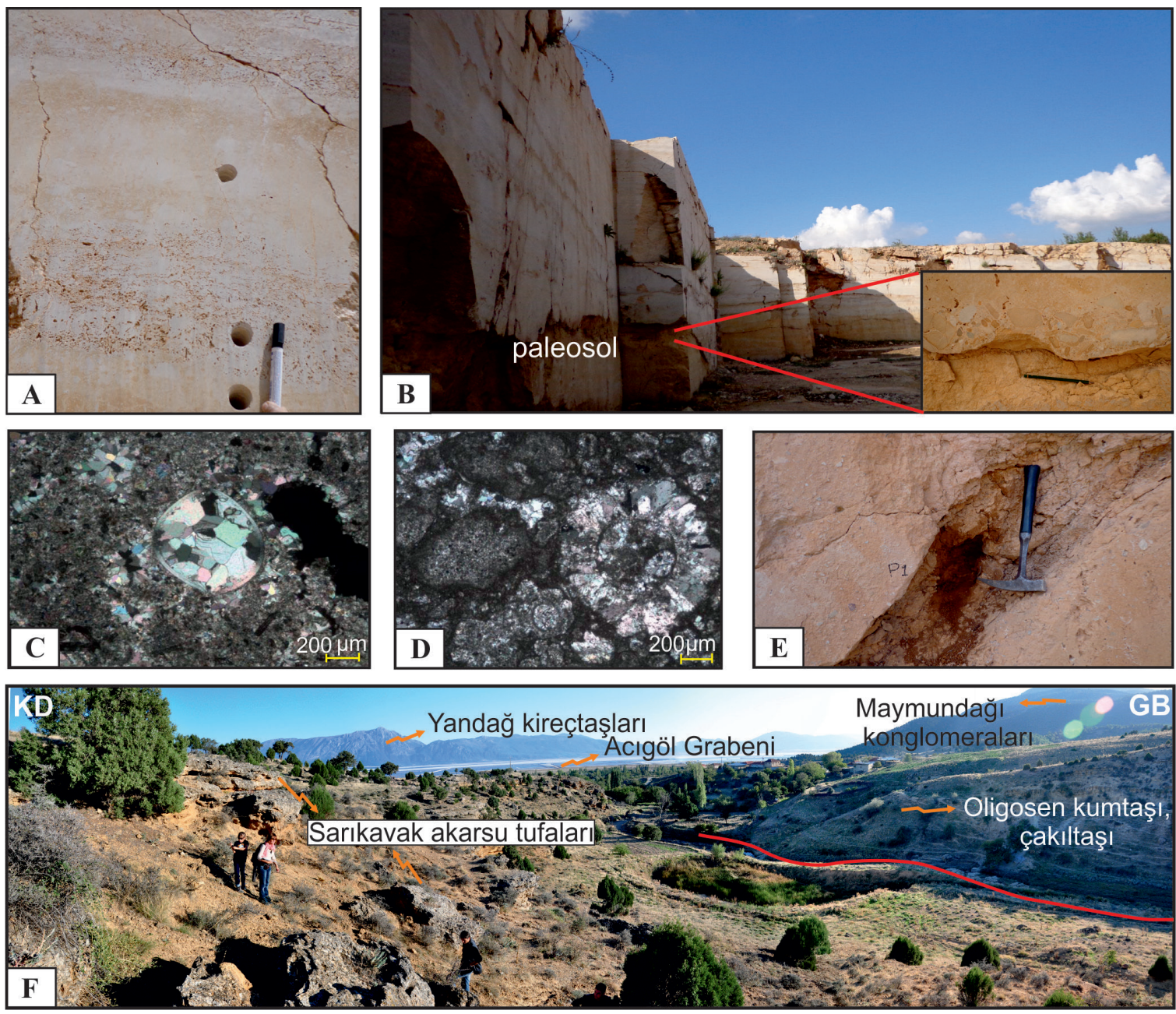

Şekil 6. (A) Örtülü travertenlerine ait çalı tipi ve havza-içi taneli litotip seviyelerinden alınan tapa örnek noktaları; (B) Terkedilmiş traverten ocağının genel görünümü (güneybatıdan kuzeydoğuya bakış) ve aşındırmalı bir şekilde kırıntılı birimin üzerine gelen havza-dışı taneler (max.çakıl boyu 12cm); (C) ostracod kavkısı, eş boyutlu bloklu spar kalsitleriyle doldurulması (çift nikol); (D) (A)'deki çalı litotipini üzerleyen havza-içi taneli birimin ince kesit görüntüsü, iki farklı yeşil alg, spar- kalsit ile yeniden kristallenmiştir;(E) traverten çökellerini kırıntılı (kahverengi renkte) birimden belirgin bir şekilde ayıran paleosol seviyesi; (F) Acıgöl Grabeni'ne doğru Sarıkavak akarsu tufalarının arazi görünümü

Figure 6. (A) The plug sample points taken from shrub and lithoclast lithotypes of Örtülü travertines; (B) The panoramic view from SE of abandoned travertine quarry and extra-clastic pebbles (max.clast size is $12 \mathrm{~cm}$ ) overlain with erosive basement on detritals; $(C)$ thin section image of ostracod shell filled by equidimensional spar calcite; (D) .thin section image from intra-clast lithotype which deposited on shrub lithotype showed in -A-and two different green algae are observed re-crystallized by spar-calcite; (E) Palaeosol level which significantly separated from detritals (brownish color) to travertine levels; (F) The field view of Sarlkavak fluvial tufas through to the Acıgöl Graben. 


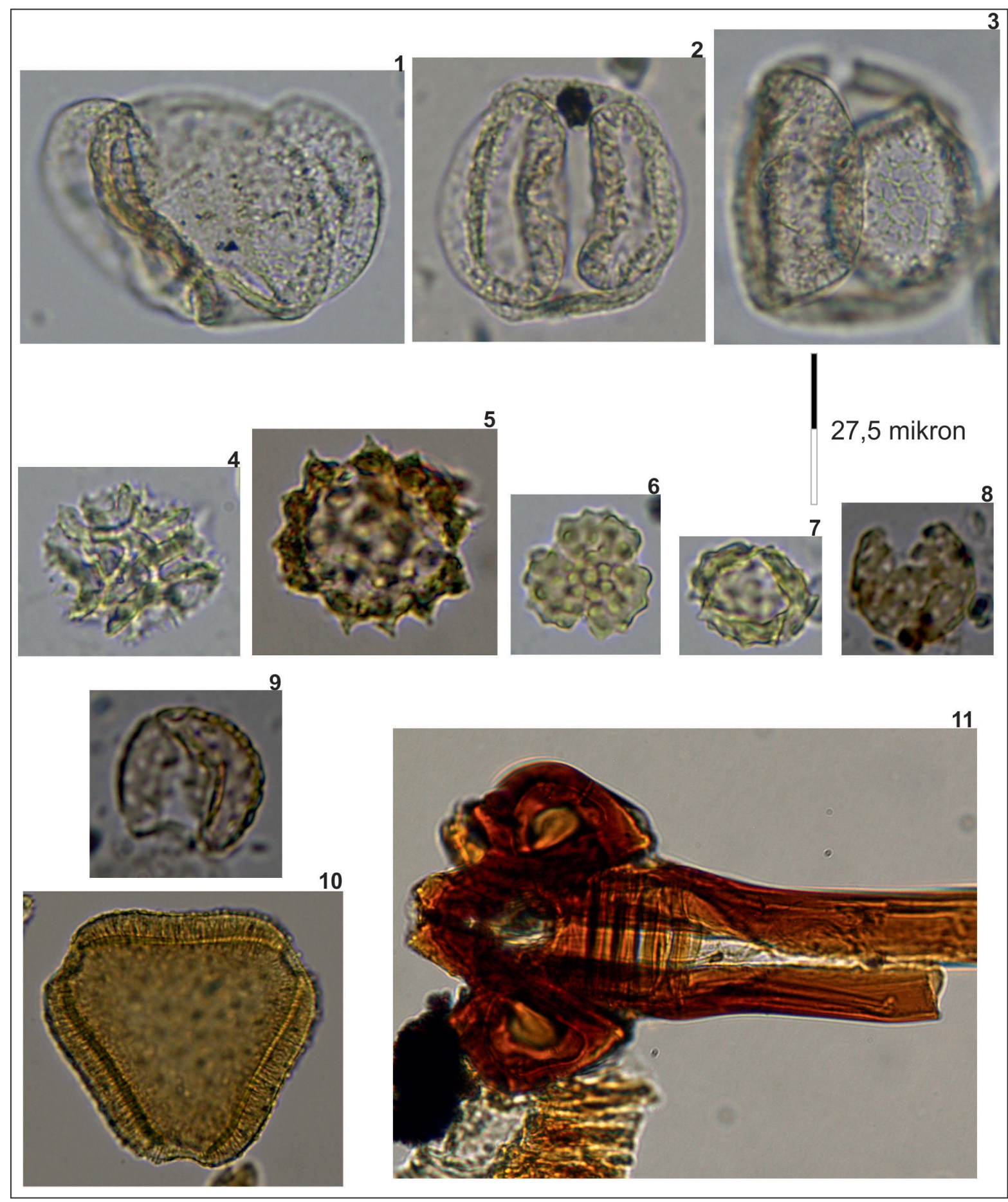

Şekil 7. Sarıkavak travertenlerinden elde edilen palinomorflar. (1-3) Pinaceae (4) Asteraceae-Cichorioideaeligulifloreae tip; (5-7) Asteraceae-tubuliflorea tip; (8,9) Chenopodiaceae; (10) Geraniaceae; (11) Zooplankton

Figure 7. The palinomorphs obtained from Sarlkavak travertenlerinden. (1-3) Pinaceae (4) AsteraceaeCichorioideae-ligulifloreae tip; (5-7) Asteraceae-tubuliflorea tip; (8,9) Chenopodiaceae; (10) Geraniaceae; (11) Zooplankton 


\section{TARTIŞMA VE SONUÇLAR}

Denizli Havzası içerisinde bulunan GürlekKocabaş travertenleri ile Acıgöl Havzasındaki Sarıkavak tufaları daha önceki çalışmalarda ayrıntılı olarak incelenmiştir (Özkul vd., 2013; Toker vd., 2015 ve Toker, 2017). Bu çalışmada, özellikle Örtülü travertenleri ile GürlekKocabaş traverten çökelleriyle olan benzerlik ve farkl1lıklar, elde edilen ilk bulgularla ortaya konulmaya çalışılmıştır. İncelenen traverten çökelleri, Orta-Geç Pleyistosen döneminde, bölgedeki aktif tektonik hareketlenmeye bağlı olarak hidrotermal suların yüzeye çıkmalarıyla sığ göl veya havuz (pool) gibi çöküntü depolanma sistemleri içerisinde depolanmış olabileceğini, ilk veriler 1şı̆̆ında söylemek mümkündür. Traverten çökelimi her zaman kesintisiz olarak devam etmemiş yer yer çeşitli nedenlerle (tektonizma, paleoiklimsel salınımlar gibi) traverten çökelimini duraksatmış ve paleosol seviyeleriyle birlikte yüksek düzeyde kırıntı girdilerinin ortamda birikmesine neden olmuştur.

Gürlek-Kocabaş travertenlerinde yatay laminalanma (mikritik traverten) belirgin olarak gözlenmekte ve maksimum kalınlığı $50 \mathrm{~cm}$ 'yi geçmeyen birkaç paleosol seviyeleri dışında kesintisiz yüzlerce metre yanal devaml1lık görülmektedir. Örtülü travertenleri ise, hem yatay laminalanma (mikritik traverten) ve hem de topoğrafya ile uyumlu bir şekilde hafif eğimli bir laminalanma sunmaktadır (Şekil 5). Güneye doğru eğimli laminalanmalarda gözlenenen mikro terasl1, kristalin kabukların (crystalline crust) varlığı, suyun akış hızına bağlı olarak ani bir depolanmanın gerçekleştiğini göstermektedir. Örtülü travertenlerinde çalı (shrub) litotipi oldukça belirgin olarak gözlenirken GürlekKocabaş travertenlerinde çalı litotipine hiç rastlanılmamaktadır. Bu litotipinin varlığg, Örtülü travertenlerinin, çalkantılı suların oluşturduğu sığ bir havuz ortamında depolanmış olabileceğini düşündürtmektedir. Örtülü travertenlerinde gözlenen bir diğer belirgin özellik, kahverengi, kiremit kırmızısı renklerinde çakı1, silt, kil gibi kırıntılıların, bu çökelme ortamını hızlı bir şekilde doldurmuş olmasıdır. Moloz akması gibi görünen bu tabaklanmasız istif, traverten çökeliminin çeşitli nedenlerle durmasıyla birlikte çökelme ortamına taşınarak havzayı neredeyse tamamen doldurmuştur. Paleosol seviyesi, moloz akması gibi görünen bu kırıntılı birim ile traverten çökelleri arasında yer almaktadır. Yaklaşı 30 cm kalınlığa sahip bu organik maddece zengin eski toprak, traverten çökeliminin duraksadığ 1 dönemde bu ortama çevreden taşınan çeşitli polenleri bünyesinde barındirmaktadır. Elde edilen ilk polen verilerine göre, genellikle otsul ve açık tohumlu bitkilere ait polenlerin varlığ (Pinaceae, Cedrus, Artemisia, Quercus) bölgede iklimsel salınımlar açısından da önemli veriler içermekte, Artemisia formunun varlığı, bu karasal karbonatların çökeliminde, serin ve kurak iklim koşullarını işaret etmektedir.

Gürlek-Kocabaş travertenlerinin kesin olarak ne zaman çökelmeye başladığı netleşmemiş olsa da traverten ocağının taban ve tavan seviyelerinden alınan U/Th yaş verileri 231 bin yıl önce de çökelimine devam etmiş olduğunu ve yaklaşık 85 bin y1l önce traverten çökeliminin tamamen durmuş söylemek mümkündür (Özkul vd., 2013; Toker vd., 2015). Ancak Örtülü travertenleri, sondajlardan elde edilen yaş verilerine göre, 500 bin yıl önce çökelmeye başlamış ve 308 bin y1l önce traverten çökeliminin durmuş olduğu elde edilen $\mathrm{U} / \mathrm{Th}$ radyometrik yaş analizi sonucunda ortaya çıkmıştır (Şekil 8). Bununla birlikte, Örtülü travertenleri, Acıgöl Graben Havzasına doğru akarsu tufalarına (Sarıkavak tufa) geçmekte ve bu tufaların tavan seviyesinden elde edilen yaş verileri 80 bin y1l önce bu bölgede karasal karbonat çökeliminin tamamen bitmiş olduğunu göstermektedir (Toker, 2017). Karşılaştırılması yapılan bu iki farklı traverten çökeline bakıldığında, hem buzul-arası ve hem de buzul dönemlerde çökelimlerine devam ettikleri görülmüştür (Şekil 8). 


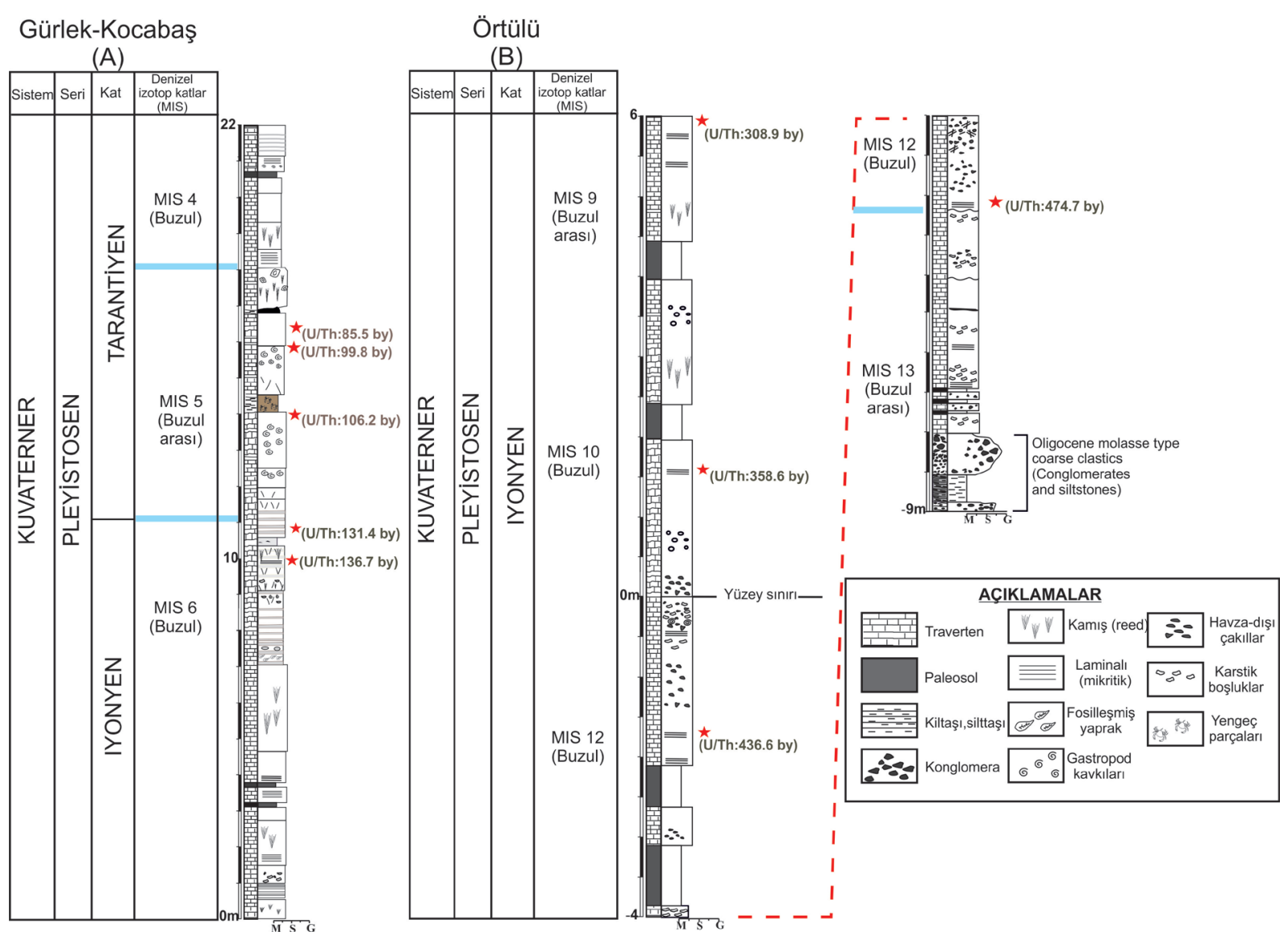

Şekil 8. Gürlek-Kocabaş (A) ve Örtülü (B) travertenlerinin araziden alınan ölçülü stratigrafik kolon kesitleri ve denizel izotopik katlarının gösterilmesi

Figure 8. Measured stratgiraphic columnar sections obtained from Gürlek-Kocabaş (A) and Örtülü (B) travertines and illustrated marine isotopic stages (MIS)

Bilindiği gibi farklı çökelme sistemleri (slope, çatlak sırtı ve havuz) içerisinde gelişen travertenlerin duraylı izotop verilerinde de farklılıklar olmaktadır (Fouke, 2000). İncelenen traverten çökellerinde duraylı izotop verilerinde bazı farklı1ıklar bulunmuştur. Gürlek-Kocabaş travertenlerindeki $\delta^{13} \mathrm{C}$ izotop değerlerinin, Örtülü travertenlerin değerlerinden biraz daha pozitif olması: 1) tektonik aktiviteye bağlı olarak hidrotermal suların dolaşımı ve hızlı $\mathrm{CaCO}_{3}$ çökelimi; 2) $\mathrm{C} 4$ bitkilerinin fazlalığı; 3) Evaporasyon etkisi gibi nedenler siralanabilir. $\mathrm{Bu}$ durumda, Örtülü travertenlerdeki az negatif değerler için, derin kökenli sularla taşınan $\mathrm{CO}_{2}$ 'in yüzey sularıyla karışarak C izotop değerlerini düşürmesi olarak yorumlanabilir.

$\delta^{18} \mathrm{O}$ duraylı izotop değerleri, incelenen iki traverten alanında da birbirlerine çok yakın değerler çıkmasına rağmen Gürlek- Kocabaş travertenlerinde biraz daha düşük negatif değerler dikkat çekmektedir. Düşük negatif $\delta^{18} \mathrm{O}$ değerleri için, göl içerisindeki evaporasyonun varlığından bahsetmek mümkündür.

İncelenen traverten çökelleri, dünyanın çeşitli yerlerindeki traverten oluşumlarıyla benzerlikler göstermektedir.Özellikletektonikhareketlenmenin yoğun olarak gözlendiği İtalya'nın merkez ve 
güney bölgelerinde hidrotermal kaynaklar geniş bir alana yayılmaktadır (Craig, 1963; Guo ve Riding, 1998; Bertini vd., 2008; Facenna vd., 2008; Brogi ve Capezzuoli, 2009; Pedley, 2009; Capezzuoli vd., 2014). Toskana Bölgesindeki Rapolano Terme' deki travertenler, Geç Pleyistosen döneminde başlayıp günümüze kadar çökelimine devam etmektedir (Guo ve Riding, 1998). İlk defa Rapolano Terme'deki travertenlerde rastlanan ve belirgin bir morfolojik özellik sunan çalı (shrub) litotipi, Örtülü travertenlerinde de belirgin olarak gözlenmiştir. Gürlek-Kocabaş ve Örtülü travertenleri gibi, Rapolano Terme'deki traverten çökellerini oluşturan suların kaynağını Üst TriyasÜst Kretase yaşlı kireçtaşları oluşturmaktadır (Guo ve Riding, 1998). Bagni di Tivoli 'deki travertenler de (Roma’nın 30 km doğusunda) morfolojik olarak güneye doğru eğimli bir çöküntü havzasında (yamaç ve çöküntü depolanma sistemi), Orta-Üst Pleyistosen döneminde çökelmişlerdir (Facenna vd., 2008).

Bu çalışmada, sedimantolojik, jeokimyasal, petrografik ve palinolojik analizler sonucu elde edilen ilk bulgular ile Gürlek-Kocabaş ve Örtülü travertenlerinin benzerlik ve farklılıkları ortaya konulmaya çalışılmıştır. Elde edilen sonuçlar, aşağıda maddeler haline verilmektedir.

- İncelenen Gürlek-Kocabaş travertenleri (Denizli Grabeni), su akış enerjisinin daha düşük, tektonizmanın yer yer etkili olduğu çöküntü depolanma sistemi içerisinde çökelirken, benzer tektonik hareketlenmelerden etkilenen Örtülü travertenleri (Acıgöl Grabeni) ise, çöküntü ve enerjinin zaman zaman yükseldiği, topoğrafyaya bağlı olarak eğimli bir laminalanma gösteren yamaç depolanma sistemleri içinde depolanmışlardır. Örtülü travertenlerinde sıkça gözlenen çalı (shrub) yapısı da sığ ve çalkantılı bir ortamı karakterize etmesi açısından oldukça önemli olup, mikro-teraslı, kristalin kabuk litotipinin görülmesi, Örtülü travertenlerinin yamaç depolanma sisteminde çökelmiş olduğunun önemli bir göstergesidir.

- Çözünme-erime yapıları, küçük mağaracıklar ve içlerinde gelişen mikro-dikitler (stalagmite) Örtülü travertenlerinin, Gürlek-Kocabaş travertenlerine göre daha karstik bir yapıya sahip olduğunu göstermektedir.

- U/Th yaş verilerine göre, Acıgöl Grabeni kuzeyinde yer alan karasal karbonat oluşumları Orta-Üst Pleyistosen döneminde oluşmuşlardır. Örtülü travertenlerine ait gerek sondaj ve gerekse yüzeyden alınan yaş verilerine göre, bu traverten çökelleri, MIS 13 (buzul arası) döneminde çökelmeye başlamış ve MIS 9 (buzul-arası) döneminde çökelme durmuştur (Şekil 8). Ancak traverten oluşumu bitmesine rağmen Acıgöl Grabeni'ne doğru (güneye) akarsu tufa çökellerine (Sarıkavak) geçiş göstererek, MIS 5 (buzul-arası) dönemine kadar çökelim devam etmiştir. Bunun yanısıra Gürlek-Kocabaş travertenleri, MIS 6 (buzul) dönemde çökelimine devam etmiş ve MIS 4 (buzul) döneminde traverten çökelimi tamamen sonlanmıştır (Şekil 8).

- Palinolojik olarak iki traverten çökelinde de paleosol seviyeleri çok zengin ancak karbonatlı seviyeler oldukça fakir çıkmıştır. Farklı zamanlara ait bu iki palinoflorada, ortamsal koşullarda farklılıklar izlenmiştir. Kocabaş travertenlerindeki paleosol dönemindeçevredeyüksek palaeotopoğrafyalı alanların varlığına işaret eden gymnosperm polenlerin varlığı ve bolluğu izlenirken, Örtülü travertenlerinin oluşumu sırasında orta yükseltideki alanların varlığından söz etmek mümkündür. Ayrıca, Örtülü travertenlerinde, serin ve kurak iklim koşullarına işaret eden Artemisia formunun varlığı bu çalışmada gözlenmiştir. Bu bölgesel ölçekte palinofloral farkl11ıkların paleotopoğrafik ve/veya paleoklimsel koşulların değişimi ile ilgili olduğu düşünülmektedir. 


\section{KATKI BELIRTME}

$\mathrm{Bu}$ çalışmada yer alan Gürlek-Kocabaş travertenleri ile ilgili elde edilen veriler, 2010BSP005 no'lu proje kapsamında desteklenmiştir. Örtülü travertenlerine ait veriler, devam eden TÜBİTAK 115Y493 no'lu proje kapsamında elde edilen bulguların bir kısmını içermektedir. Palinolojik verilerin tanımlanmasinda ve polenlerin, paleoortam ve paleoiklim değişimlerindeki rolü üzerinde yardımlarını esirgemeyen Adele Bertini'ye ve M. Sezgül Kayseri-Özer'e sonsuz teşekkürlerimi sunarım. Ayrıca makalenin gelişmesinde ve yayınlanmasında değerli görüş ve önerileriyle katkı sağlayan Hasan Sözbilir'e ve ismi verilmeyen diğer hakemlere teşekkürü bir borç bilirim.

\section{EXTENDED SUMMARY}

Denizli (NW-SE trending) and Acrgöl Basins (NESW trending) are crosscut grabens which developed during the Neotectonic extensional period of SWTurkey. Denizli graben basin is spectacular place for terrestrial calcium carbonate deposits along the northern margin of the graben side. On the other hand, Actgöl graben basin which is peculiar playa lake in the center of graben called Actgöl lake and also several hydrothermal springs along the southern margin of the graben side.

Investigated areas are Gürlek-Kocabaş and Örtülü travertines located at the southeastern of the Denizli and northern side of the Actgöl grabens, respectively. In this study, shallow lake travertine deposits located in Gürlek-Kocabaş (Denizli) and Örtülü (Afyon) settlements have been aimed at comparison with palaeoenvironmental development using by detailed field observation and several analysis such as stable isotope, U/ Th radiometric dating, palynology and some petrographic analysis.

The Gürlek-Kocabaş travertines are extended hundered meters and approximately up to $60 \mathrm{~m}$ thickness. The lithotypes are mainly composed of laminated, gas bubbles, reeds, paper-thin raft, intra-clast and extra-clast breccias. These lithotypes characterize marsh-pool and flatpool facies which deposited in shallow-lake or depression depositional system. On the other hand, the lateral extended of Örtülü travertine deposits is several hundered meters and the thickness is up to 20m. Moreover, the lithotypes differently from the Gürlek-Kocabaş travertines lithotypes, are represented by crystalline crust and shrubs. The lithotypes of these deposits indicate smooth slope and terraced slope facies formed in slope depositional system which is related to higher flowing energy. In addition, flat-pool and shrubflat facies are also observed in Örtülü travertine deposits which formed turbulated shallow-lake or depression depositional system (Çizelge 1). Palaeosol levels are quite common detrital inputs between travertine accumulations. Accoding to stable isotopic results, $\delta^{13} \mathrm{C}$ stable isotopic values are between $1.4 \%$ and $2.6 \%$ (V-PDB) in Gürlek-Kocabaş and between $-1.54 \%$ and $1.5 \%$ $(V-P D B)$ in Örtülü travertines. $\delta^{18} O$ values show that Gürlek-Kocabaş and Örtülü travertines are quite close values; $-10.5 \%$ ile -6.4\%o (V-PDB) in Gürlek-Kocabaş and -10.78\%o ile -9.76\%o (V-PDB) in Örtülü travertines.

Palynomorphs represented by gymnosperm and herbal angiosperm pollen are scarcely observed in the travertine samples, however these microfloral elements abundant in the palaeosol samples in the Örtülü travertine deposits. Palynoflora defined in the palaeosol level is especially characterized by herb species (Poaceae, Asteraceae-Tubuliflorea, Artemisia, Asteraceae-Cichorioideae-ligulifloreae, Polygonum persicaria, Geraniaceae and Chenopodiaceae). Besides, angiosperm (i.e. Quercus, Castanea) and gymnosperm pollen (i.e. Pinaceae, Cedrus) are accompanied with these species in the samples. Non pollen palynomorphs and other organic material abundantly recorded. This palinofloral data indicates that cold and dry climatic condition could be occurred during the 
deposition of palaeosol levels. The both travertine occurences continued to precipitate either interglacial and or glacial periods.

According to U/Th dating, Örtülü travertine accumulations ceased approximately $308 \mathrm{ka}$ ago and later travertine precipitations laterally pass to fluvial tufa (Sarlkavak tufa) deposits to the Acıgöl graben. Moreover, Gürlek-Kocabaş travertine deposits continued to precipitate until $85 \mathrm{ka}$. The differences of these travertine accumulations are the most probably related with hydrothermal water input controlled by tectonic activity during Neotectonic period.

\section{ORCID}

Ezher Toker (D)

http://orcid.org/0000-0002-1774-5012

\section{DEĞİNILEN BELGELER}

Alçiçek, H., Varol, B. ve Özkul, M., 2007. Sedimentary facies, depositional environments and palaeogeographic evolution of the Neogene Denizli Basin of SW Anatolia, Turkey. Sedimentary Geology 202, 596-637.

Altunel, E. ve Hancock, P.L., 1993a. Morphology and structural setting of Quaternary Travertines at Pamukkale, Turkey. Geological Journal, 28, 335 -346 .

Altunel, E. ve Hancock, P.L., 1993b. Active fissuring faulting in Quaternary travertines at Pamukkale, Western Turkey: In: Neotectonics and Active Faulting (edited by Stevvart, 1. S.,

Vita.Finzi, c. \& Ovven, L. A.) Zeitschrift Geomorphologie Supplementary Volume, 94, 285-302.

Altunel, E., 1996. Pamukkale travertenlerinin morfolojik özellikleri, yaşları ve neotektonik önemleri, MTA Dergisi, 118, 47-64.

Altunel, E. ve Karabacak, V., 2005. Determination of horizontal extension from fissure ridge travertines: a case study from the Denizli Basin, southwestern Turkey. Geodinamica Acta 18, 333-342.
Andrews, J.E., Riding, R. ve Dennis, P.F., 1997. The stable isotope record of environmental and climatic signals in modern terrestrial microbial carbonates from Europe. Palaeogeography, Palaeoclimatology, Palaeoecology, 129, 171-189

Andrews, J.E., Pedley, H.M. ve Dennis, P.F., 2000. Palaeoenvironmental records in Holocene Spanish tufas: a stable isotope approach in search of reliable climatic archives. Sedimentology, 47, 961-978.

Bozkurt, E. ve Oberhansli, R., 2001. Menderes Massif(western Turkey): structural, metamorphic and magmatic evolution-a synthesis. International Journal of Earth Sciences, 89, 679-708.

Brogi, A. ve Capezzuoli, E., 2009. Travetine deposition and faluting: the fault-related travertine fissureridge at Terme S. Giovanni, Rapolano Terme (Italy). International Journal of Earth Science Geology Rundsch 98, 931-947.

Brogi, A., Capezzuoli, E., Aqué, R., Branca, M. ve Voltaggio, M., 2010. Studying travertine for neotectonics investigations: Middle-Late Pleistocene syntectonic travertine deposition at Serre di Rapolano (northern Appennines, Italy). International Journal of Earth Sciences, 99, 13831398.

Chafetz, H.S. ve Folk, R.L., 1984. Travertines: Depositional morphology and the bacterially constructed constituents. Journal Sedimentary Petrology, 54 (1), 289 - 316.

Craig, H., 1963. The isotope geochemistry of water and carbon in geothermal areas. Nuclear Geology on Gethermal Areas. Spoleto.(E. Tongiorni, Ed.) Consiglio Nazionale delle Ricerche, Laboratorio di Geologic Nucleare, Pisa, 17-53.

Çakır, Z. 1999. Along-strike discontinuty of active normal faults and its influence on Quaternarytravertine deposition: Examples from western Turkey. Turkish Journal of Earth Science, $8,67-80$.

De Filippis, L., Faccenna, C., Billi, A., Anzalone, E., Brilli, M., Özkul, M., Soligo, M., Tuccimei, P. ve Villa, M., 2012. Growth of fissure ridge travertines from geothermal springs of Denizli Basin, western Turkey. Bulletin of the Geological Society of America 124, 1629-1645. 
Dilsiz, C., 2006. Conceptual hydrodynamic model of the Pamukkale hydrothermal field, southwestern Turkey, based on hydrochemical and isotopic data. Hydrogeology Journal 14, 562-572.

Erdoğan,B. ve Güngör, T. 2004. The problem of the corecover boundary of the menderes massif and an emplacement mechanism for regionally extensive gneissic granites, western Anatolia (Turkey). Turkish Journal of Earth Sciences 13, 15-36.

Ford, T.D. ve Pedley, H.M., 1996. A review of tufa and travertine deposits of the world, Earth Science Review, 41, 117-175.

Gandin, A. ve Capezzuoli, E., 2014. Travertine: Distinctive depositional fabrics of carbonates from thermal spring systems, Sedimentology, 61, 264-290.

Garnett, E.A., Andrews, J.E., Preece, R.C. ve Dennis, P.F., 2004. Climatic change recorded by stable isotopes and trace elements in a British Holocene tufa. Journal of Quaternary Science, 19, 251-262.

Göktaş, F., Çakmakoğlu, A., Tari, E., Sütçü, Y. F. ve Sarikaya, H., 1989. Çivril -Çardak Arasının Jeolojisi (Geology of Çivril-Çardak Region]. MTA Raporu, 8701, 107s (yayınlanmamış)..

Guo, L. ve Riding, R., 1998. Hot-spring travertine facies and sequences, Late Pleistocene Rapolano Terme, Italy, Sedimentology, 45, 163-180.

Guo, X. ve Chafetz, H.S., 2014. Trends in $\delta^{18} \mathrm{O}$ and $\delta^{13} \mathrm{C}$ values in lacustrine tufa mounds: Palaeohydrology of Searles Lake, California. Sedimentology, 61, 221-237.

Hancock, P.L., Chalmers, R. M.L., Altunel E. ve Çakir, Z., 1999. Travitonics: using travertines in active fault studies. Journal of Structural Geology, 21, 903-916.

Helvacı C., Alçiçek, M.C., Gündoğan, İ. ve Gemici, Ü., 2013. Tectonosedimentary Development and Palaeoenvironmental Changes in the Acıgöl Shallow-Perennial Playa-Lake Basin, SW Anatolia,Turkey. Turkish Journal of Earth Science, 22, 173-190.

İslamoğlu, Y. ve Hakyemez, A., 2010. Oligocene History of the Çardak-Dazkırı Sub-basin (Denizli, SW Turkey): Integrated Molluscan and Planktonic Foraminiferal Biostratigraphy. Turkish Journal of Earth Science, 19, 473-496.
Kaymakc1, N., 2006. Kinematic development and paleostress analysis of the Denizli Basin (Western Turkey): Implications of spatial variation of relative paleostress magnitudes and orientations. Journal of Asian Earth Sciences, 27, 207222.10.1016/j.jseaes.2005.03.003.

Koçyiğit, A., 2005. Denizli-graben horst system: basin fill, structure, deformational mode, throw amount and episodic evolutionary history, SW Turkey, Geodinamica Acta, 18 (3-4), 167-208.

Konak, N. ve Şenel, M., 2002. Türkiye jeoloji haritası, Denizli paftası 1: 500 000. Maden Tetkik ve Arama Genel Müdürlüğü, Ankara.

Koşun, E., Sarıül, A. ve Varol, B., 2005. Antalya Tufalarının Litofasiyes Özellikleri. MTA Dergisi, 130, 57-70.

Lojen, S., Dolenec, T., Vokal, B., Cukrov, N., Mihelčić, G. ve Papesch, W., 2004. C and O stable isotope variability in recent freshwater carbonates (River Krka, Croatia). Sedimentology, 51, 361-375.

Miall, A.D., 1977. A review of the braided river depositional environment: Earth Science Review,13, 1-62.

Minissale, A., Kerrick, D. M., Magro, G., Murrell, M. T., Paladini, M., Rihs, S., Sturchio, N. C., Tassi, F. ve Vaselli, O., 2002. Geochemistry of Quaternary travertines in the region north of Rome (Italy): structural, hydrologic and paleoclimatic implications. Earth and Planetary Science Letters, 203, (2), 709-728.

Mutlu, H., Kadir, S. ve Akbulut, A.,1999. Mineralogy and water chemistry of the Lake Acıgöl (Denizli), Turkey. Carbonates and Evaporites 14, 91-99.

Özkul, M. Varol, B. ve Alçiçek, M.C., 2002. Depositional environments and Petrography of Denizli Travertines. Bulletin of the Mineral Research and Exploration, 125, 13-29.

Özkul, M., Kele, S., Gökgöz, A., Shen, C.C., Jones, B., Baykara, M.O., Fórizs, I., Németh, T., Chang, Y.W. ve Alçiçek, M.C., 2013. Comparison of the Quaternary travertine sites in the Denizli extensional basin based on their depositional and geochemical data. Sedimentary Geology, 294, 179-204. 
Özkul, M., Gökgöz, A., Kele, S., Baykara, M.O., Shen, C.C., Chang, Y.W., Kaya, A., Hançer, M., Aratman, C., Akın, T. ve Örü, Z., 2014. Sedimentological and Geochemical characteristics of a fluvial travertine: A case from the eastern Mediterreanean region. Sedimentology, 61, 291-318.

Pedley, H.M., 2009. Tufas and travertines of the Mediterranean region: a testing ground for freshwater carbonate concepts and developments. Sedimentology, 56, 221-246.

Pentecost, A., 1993. British travertines: a review, Proceeding of the Geologists' Association, 104, 23-39.

Pentecost, A., 1995. Quaternary travertine deposits of Europe and Asia Minor. Quaternary Science Review, 14, 1005-1028.

Pentecost, A., Bayarı, S. ve Yeşertener, C., 1997. Phototropic microorganisms of the Pamukkale travertine, Turkey; their distribution and influence on travertine deposition. Geomicobiology Journal, 14, 264-283.

Pentecost, A., 2005. Travertine. Springer, Berlin, 445.

Sözbilir, H., 1997. Stratigraphy and Sedimentation of the Tertiary Sequences in the Northeastern Denizli Province (Southwest Turkey). (Doktora Tezi), Dokuz Eylül Üniversitesi Mühendislik Fakültesi (yayınlanmamış).

Sözbilir H., 2002. Revised stratigraphy and facies analysis of the Palaeocene-Eocene supraallochthonous sediments and their tectonic significance (Denizli, SW Turkey). Turkish Journal of Earth Sciences 11, 1-27.

Sözbilir, H., 2005. Oligo-Miocene extension in the Lycian orogen: evidence from the Lycian molasse basin, SW Turkey. Geodinamica Acta, 18 (3-4), 255-282.

Sun, R. S., 1990. Denizli-Uşak Arasının Jeolojisi ve Linyit Olanakları. İzmir, MTA Raporu, No 9985.

Şenel, M., 1997. Denizli-J9 Quadrangle, 1:100.000 ölçekli Jeoloji haritası ve açıklamaları. MTA Yayınları, Ankara (yayınlanmamış)

Şimşek, Ş., Günay, G., Elhatip, H., Ekmekci, M., 2000. Environmental protection of geothermal waters and travertines at Pamukkale, Turkey. Geothermics 29, 557-572.
Toker, E., 2009. Acıgöl-Çardak (Denizli) Grabeninin kuzeyindeki Tersiyer Çökellerinin TektonoSedimanter Gelişiminin İncelenmesi. (Doktora tezi), Süleyman Demirel Üniversitesi, 242 (yayınlanmamış).

Toker, E., Akkiraz, M.S., Yağmurlu, F., Akgün, F. ve Örçen, S., 2012. Sedimentary Properties of the Middle-Late Eocene Formations outcroping in Çardak, Burdur and İncesu, SW Turkey. Turkish Journal of Earth Science, 20, 335-374.

Toker, E., Kayseri-Özer, M.S., Özkul, M. ve Kele, S., 2015. Depositional system and palaeoclimatic interpretations of Middle to Late Pleistocene travertines: Kocabaş, Denizli, SW Turkey. Sedimentology, 62 (5), 1360-1383.

Toker, E., 2016. The Quaternary Travertınes in the Örtülü Area, SW- Turkey: Facies And Depositional Environment. 32. IAS Meeting of Sedimentology, 23-25 Mayıs, Marakeş, Fas

Toker, E., 2017. Quaternary fluvials tufas of Sarkavak area, southwestern Turkey: Facies and depositional systems. Quaternary International, Non-marine Carbonates, Special Issue, 437, 37-50.

Uysal, I.T., Feng, Y., Zhao, J., Altunel E., Weatherley D., Karabacak, V., Cengiz, O., Golding S.D., Lawrence M.G. ve Collerson K.D., 2007. U-series dating and geochemical tracing of late Quaternary travertine in co-seismic fissures. Earth and Planetary Science Letters, 257, 450-462.

Uysal, I.T., Feng, Y., Zhao, J., Işık, V., Nuriel, P. ve Golding, S.D., 2009. Hydrothermal CO2 degassing in seismically active zones during the late Quaternary. Chemical Geology, 265, 442-454.

Van Noten, K., Claes, H., Soete, J., Foubert, A., Özkul, M. ve Swennen, R., 2013. Fracture networks and strike-slip deformation along reactivated normal faults in Quaternary travertine deposits, Denizli Basin, western Turkey. Tectonophysics 588, 154170.

Vermoere, M., Degryse, P., Vanhecke, L., Muchez, Ph., Paulissen, E., Smets, E. ve Waelkens, M., 1999. Pollen analysis of two travertine sections during the early Holocene in Baskoy (southwestern Turkey): implications for environmental conditions during the early Holocene. Review of Paleobotany and Palynology, 105, (1-2), 93-110. 
Westaway, R., Guillou, H., Yurtmen, S., Demir, T., Scaillet, S. ve Rowbotham, G., 2005. Constraints on the timing and regional conditions at the start of the present phase of crustal extension in western Turkey, from observations in and around the Denizli region. Geodinamica Acta 18, 209-238.

Yılmaz, Y., Genç, Ş.C., Gürer, F., Bozcu, M., Yılmaz, K., Karacık, Z., Altunkaynak, Ş. ve Elmas, A., 2000. When did the western Anatolian grabens bagin to develop? Tectonic and magmatism in
Turkey and their surrounding area. Geological Society in London, 173, 353-384.

Zanchi, A., Kissel, C. ve Tapırdamaz, C., 1990. Deformazione Continentale NeogenicoQuaternaria in Anatolia Occidentale:Nuovi DAti Strutturali. Mem. Society of Geology Italy, 45, 481-488. 